\title{
ANÁLISE DA RELAÇÃo ENTRE OS NÍVEIS DE RENDA E RENDA PER CAPITA ESTADUAIS E O COMÉRCIO POR VIAS INTERNAS NO BRASIL: UMA ABORDA- GEM COM DADOS EM PAINEL PARA OS ANOS DE 1998, 1999 E 2008
}

Resumo: O artigo tem o objetivo de analisar o comércio inter-regional das regiões brasileiras, mediante a observação das relações estaduais inerentes à própria região, bem como as relações concernentes às demais regiões. Pretende-se ainda verificar-se como tais fluxos de comércio relacionam-se com os níveis de renda e renda per capita estaduais. Para tanto a metodologia consistiu em estimar modelos de dados em painel não espacial com efeitos fixos (EF) e aleatórios (EA) que relacionam tais variáveis. Os fluxos de comércio inter-regionais foram obtidos a partir de Vasconcelos (2001), Vasconcelos e Oliveira (2006) e de Guilhoto et al. (2010). Os resultados apontam para o alto grau de dependência comercial das demais regiões em relação à região Sudeste (em especial ao estado de São Paulo). Verifica-se uma grande concentração dos fluxos de comércio originados da porção centro-sul do país e, em geral, os fluxos interestaduais têm importância relativa maior para os estados menos desenvolvidos do país. Tem-se uma relação positiva entre o comércio inter-regional e o produto regional bruto, todavia, no nível agregado, capta-se uma relação negativa dos fluxos de comércio com o PIB per capita.

Palavras-chave: Comércio Inter-regional. Fluxos Comerciais. Produto Regional.

\section{ANALYSIS OF THE RELATIONSHIP BETWEEN INTERREGIONAL TRADE, IN- COME LEVEL AND PER CAPITA STATE INCOME LEVEL IN BRAZIL: A PANEL DATA APPROACH FOR THE YEARS 1998, 1999 AND 2008}

\begin{abstract}
The paper aims to analyze the interregional trade of the Brazilian regions, by observing the inherent relations of the region and the relations with other regions. It is intended to also check how trade flows are related to GDP and GDP per capita. The methodology consists in estimating the non-spatial panel data models that relate to the variables. Interregional trade flows were obtained from Vasconcelos (2001), Vasconcelos and Oliveira (2006) and Guilhoto et al. (2010). The results show the high degree of commercial dependence on other regions in relation to the South-East region (in particular the State of São Paulo). There is a great concentration of trade flows in the central-south part of the country and, in general, interstate flows are of greater relative importance for the less developed states of the country. There is a positive relationship between interregional trade and GDP. However, at the aggregate level, a negative relation with GDP per capita is observed.
\end{abstract}

Keywords: Inter-regional Trade. Trade Flows. Regional Product.

\footnotetext{
${ }^{1}$ Universidade Federal do Rio Grande do Norte - UFRN, Departamento de Economia, Natal/RN, Brasil, joelsonsantosrdp@hotmail.com, https://orcid.org/0000-0001-9689-9505

2 Universidade Federal do Rio Grande do Norte - UFRN, Departamento de Economia, Natal/RN, Brasil, andre.Iclourenco@gmail.com, https://orcid.org/0000-0001-6374-7302
} 


\section{ANÁLISIS DE LA RELACIÓN ENTRE LOS NIVELES DE RENTA Y RENTA PER CAPITA ESTADUALES Y EL COMERCIO POR VÍAS INTERNAS EN BRASIL: UN ENFOQUE CON DATOS EN PANEL PARA LOS AÑOS DE 1998, 1999 Y 2008}

Resumen: El presente trabajo busca analizar el comercio interregional de las regiones brasileñas, observando las relaciones inherentes de la región y las relaciones con otras regiones. También se pretende verificar como se relacionan los flujos comerciales con el PIB y el PIB per capita. La metodología consiste en estimar los modelos de datos de panel no espaciales que se relacionan con las variables. Los flujos comerciales interregionales se obtuvieron de Vasconcelos (2001), Vasconcelos y Oliveira (2006) y Guilhoto et al. (2010). Los resultados muestran el alto grado de dependencia comercial de otras regiones en relación con la región sudeste (en particular, el estado de São Paulo). Existe una gran concentración de flujos comerciales en la parte centro-sur del país y, en general, los flujos interestatales son de mayor importancia relativa para los estados menos desarrollados del país. Existe una relación positiva entre el comercio interregional y el PIB. Sin embargo, a nivel agregado, se observa una relación negativa con el PIB per capita.

Palabras clave: Comercio Interregional. Flujos Comerciales; Producto Regional.

\section{Introdução}

O comércio entre regiões permite a circulação de produtos nos quais as mesmas possuem vantagens competitivas, bem como prover a demanda por produtos que por algum motivo não conseguem atender. De acordo com Haddad (2003), as economias regionais não são simplesmente versões em menor escala das economias nacionais. Elas apresentam especificidades tais que se fazem necessárias teorias próprias que versem sobre o processo de desenvolvimento regional. Em geral, devido aos contatos mais estreitos e às interações mais intensas que existem entre as regiões de um país, tanto o efeito de transbordamento do crescimento quanto os efeitos de polarização são mais fortes nas relações econômicas inter-regionais do que nas internacionais. Neste sentido, as forças políticas que contribuem para a transmissão inter-regional do crescimento são, provavelmente, mais poderosas do que as que contribuem para a transmissão internacional (HADDAD, 2003).

A integração regional brasileira teve seu arrefecimento na década de 1950, segundo Galvão (1993) antes dos anos 50 o comércio inter-regional no Brasil era pequeno e, praticamente, realizado por meio de cabotagem, o que dificultava a intensificação dos fluxos comerciais entre as regiões brasileiras. Para o autor, até então havia uma situação em que o sistema comercial brasileiro era "um arquipélago 
de ilhas econômicas isoladas", onde o comércio ocorria principalmente dentro das próprias regiões.

Como consequência "foi apenas após a efetivação de um programa nacional de construção de rodovias nos anos 50 e 60 que o Brasil, rompeu, de fato, com o estado de relativo isolamento de suas economias regionais" (GALVÃO, 1993, p. 524).

Haddad e Perobelli (2002) apud Haddad (2003), em estudo que versa sobre a integração nacional e o padrão de comércio inter-regional dos estados brasileiros no fim da década de 90, apontam algumas características do sistema comercial interestadual: i) os percentuais de exportações interestaduais e internacionais sobre o PIB dos estados brasileiros são muito elevados; ii) para todos os estados, as exportações interestaduais superam, em maior ou menor escala, as exportações internacionais evidenciando, portanto, a importância de estudos que contemplem análises dos fluxos de comércio interestaduais; iii) verifica-se grande concentração dos fluxos de comércio originados da porção Centro-Sul do país; iv) em geral, os fluxos interestaduais têm importância relativa maior para os estados menos desenvolvidos. Portanto, tomando por base os autores, o futuro de certas regiões e estados talvez esteja significantemente ligado à sua articulação as demais regiões, ou seja, ao mercado doméstico.

O comércio inter-regional pode tornar-se um propulsor do crescimento regional e/ou perpetuar as disparidades regionais em um determinado país. Perobelli et al. (2008) argumentam que as interações inter-regionais, dentre outros fatores, são importantes ao desenvolvimento de uma região. Estes autores apontam ainda que é inquestionável a necessidade de um maior número de estudos recentes para tais interações.

Dada à importância do tema salientada na literatura e partindo da hipótese de que a maior integração comercial entre os estados relaciona-se positivamente com maiores níveis de renda, este trabalho tem como objetivo geral analisar o comércio inter-regional das regiões brasileiras, identificando os fluxos comerciais intrarregionais e transregionais para as cinco regiões brasileiras nos anos de $1998 \mathrm{e}$ 2008, mediante a observação das relações estaduais inerentes à própria região, bem como as relações concernentes às demais regiões. Pretende-se ainda verificar se e como tais fluxos de comércio relacionam-se com os níveis de renda e renda per capita estaduais. 
A metodologia consistiu em estimar modelos de dados em painel não espacial com efeitos fixos (EF) e aleatórios (EA) que relacionam tais variáveis. Tal uso deveuse à disponibilidade de dados de corte para todos os estados brasileiros, mas em poucos pontos no tempo ${ }^{3}(1998,1999$ e 2008).

Para atender-se aos objetivos propostos utiliza-se como indicadores do fluxo de comércio inter-regional a corrente de comércio (soma de todas as exportações e importações do período, ou seja, exportações e importações de bens e serviços finais e intermediários) e o saldo geral da balança comercial e de serviços (soma de todas as exportações de bens e serviços menos a soma de todas as importações de bens e serviços) ponderados pelos produtos regionais brutos estaduais.

Para o ano de 1998 e 1999, os fluxos de comércio das regiões brasileiras e seus respectivos estados foram obtidos a partir de Vasconcelos (2001) e Vasconcelos e Oliveira (2006). Tais trabalhos tiveram como base a análise da matriz por atividade econômica do comércio interestadual. A partir da estimação das matrizes de insumo-produto (MIPs) para os vinte e seis estados brasileiros e o Distrito Federal empreendida por Guilhoto et al. (2010), foi possível obter os fluxos de comércio para o ano de 2008.

Além desta introdução, compõem o trabalho mais cinco seções. Na primeira seção faz-se uma revisão de trabalhos empíricos anteriores sobre o comércio interregional brasileiro. Na segunda analisa-se como se dá a distribuição da corrente de comércio regional para o país, realiza-se a subdivisão desta em termos intrarregionais e transregionais, bem como verifica-se como se dá a integração comercial regional entre os estados, mediante a análise do destino das exportações e origem das importações dos estados que compõem as regiões brasileiras. $\mathrm{Na}$ terceira seção observa-se o saldo da balança comercial e de serviços das regiões brasileiras ponderados por seus respectivos PIBs. Ademais, tal como na seção anterior, realiza-se a subdivisão deste saldo em termos intrarregionais e transregionais e analisam-se os saldos de uma determinada região em relação às demais. Na quarta seção verifica-se como os fluxos de comércio relacionam-se com os níveis de renda e renda per capita estadual. Por fim a quinta seção destina-se as considerações finais.

\footnotetext{
${ }^{3}$ Devido à carência quanto à disponibilidade de dados e informações sobre os fluxos de comércio por vias internas não foi possível ampliar a análise para outros períodos.
} 


\section{Revisão de literatura}

Esta seção destina-se a revisar trabalhos empíricos selecionados que tratam do comércio inter-regional brasileiro. O critério de seleção consistiu na cobertura de dados sobre diferentes períodos históricos.

Galvão (1993) analisa o comércio inter-regional e intrarregional através de 4 matrizes do comércio interestadual para os anos de 1943, 1947, 1961 e 1969. Segundo o autor, até a metade do século 20, o comércio inter-regional brasileiro era ainda incipiente e a pauta de exportações estaduais voltava-se principalmente ao mercado internacional. A partir dos anos 50 houve uma considerável reversão deste quadro, dado que as relações entre os estados se intensificaram ao ponto do comércio inter-regional superar o comércio internacional.

Galvão, ao comparar as matrizes das décadas de 1940 e as de 1960, aponta as principais mudanças ocorridas: i) em 1943 e 1947 o comércio transregional das unidades da Federação situava-se em torno de 18 e $20 \%$ dos fluxos totais de comércio por vias internas, ao passo que em 1961 e 1969 tais fluxos aumentam substancialmente, para respectivamente $45 \%$ e $47 \%$ desses fluxos; ii) o comércio da região Norte, até então predominantemente intrarregional, passou a majoritariamente transregional; iii) no Nordeste, apesar da predominância do comércio intrarregional, registrou-se significativa expansão do seu grau de abertura com respeito as demais regiões do país, pois 33\% de suas exportações foram destinadas as demais regiões do país, e 50\% de suas importações foram oriundas de outras regiões; iv) houve expressivo aumento do grau de abertura da região Sudeste, com seu comércio transregional aumentando sua participação nas exportações por vias internas da região de 12\% em 1943 e 1947 para 36\% em 1961; v) as regiões Centro-Oeste e Sul mantiveram os mesmos padrões das décadas anteriores, isto é, um comércio transregional intenso, relativamente ao total de seu comércio por vias internas.

Cano (1985), por seu turno, analisa o comércio inter-regional do estado de São Paulo com o resto do país, no período de 1928 a 1968. As principais observações do autor vão de encontro ao apontado por Galvão (1993), maior integração do mercado doméstico nacional a partir de 1950, dado que as exportações de São Paulo para os demais estados se elevam consideravelmente em relação às suas exportações internacionais.

Pacheco (1998), por sua vez, através do estudo da balança comercial interestadual do país e seus respectivos estados entre 1975 e 1985, verifica que, no 
período em análise, a despeito do ocorrido entre 1943 e 1969, para muitos estados brasileiros ocorreu um decréscimo ou estagnação no comércio por vias internas, à exceção dos estados da Bahia e do Amazonas, respectivamente, devido à instalação do Polo Petroquímico de Camaçari e da Zona Franca de Manaus. Para o autor, o período conjuntural recessivo que caracteriza o início da década de 1980 pode explicar essa reversão no comportamento dos fluxos de comércio interestaduais.

Pautando a análise em dados para o início dos anos 90, Pacheco (1998) também mostra a concentração das pautas de exportações para a maioria das regiões. São Paulo e a região Sul são as localidades que apresentam maior diversificação da pauta. Na região Norte, os produtos de origem mineral eram responsáveis por $70,3 \%$ de suas exportações. Já na região Centro Oeste, o complexo produtivo da soja representava $65 \%$ da pauta de exportações regionais.

Castro et al. (1999) analisaram o quadro da distribuição do comércio interestadual brasileiro em 1985, e concluíram que tal quadro apresentava forte concentração espacial. A maioria das exportações e importações fora realizada por um pequeno número de estados, basicamente concentrados em duas das cinco macrorregiões (Sul e Sudeste) do território nacional. Poucos também foram os estados que apresentaram superavit na Balança Comercial Interestadual. Essa concentração das relações de comércio refletia, em certa medida, a elevada concentração espacial da atividade econômica, especialmente industrial, então existente no país.

Vasconcelos e Oliveira (2006) realizaram análise descritiva da pauta de exportações (vias internas) por atividade econômica em 1999, para as unidades da Federação. Apontaram que: i) na região Sudeste, o estado de São Paulo respondeu pela maioria das compras efetuadas pelos outros estados do país. Ademais, há elevada participação deste nas da própria região Sudeste e da região Sul (66\% do total de suas transações comerciais), em detrimento das demais regiões, corroborando a "desigual distribuição da renda brasileira" (VASCONCELOS; OLIVEIRA, 2006, p. 9); ii) o principal destino das exportações interestaduais dos estados pertencentes a região Sul são, em primeiro lugar São Paulo, que responde por parcela significativa das compras sulinas, e em segundo lugar os estados da própria região (comércio intrarregional); iii) o Centro Oeste é marcado pela concentração das exportações para São Paulo (principalmente), Paraná e Minas Gerais. Ademais, apresenta pauta de exportação interestadual fortemente atrelada a 
produtos alimentícios, bebidas e agropecuária; iv) quanto aos estados nordestinos, nota-se a predominância do comércio intrarregional, dado que, exceto Bahia, as exportações destes estados para as demais macrorregiões do país tem como principal destino a própria região; v) no Norte, o estado do Amazonas destaca-se pela significativa cifra de exportação atrelada aos estados de São Paulo e Rio de Janeiro, principalmente no que se refere a material eletrônico e aparelhos e equipamentos de comunicações, em função da Zona Franca de Manaus. Ademais, os principais importadores da região encontram-se na região Sudeste.

Almeida e Silva (2007) utilizaram o modelo gravitacional com a finalidade de mensurar e comparar o efeito fronteira existente no comércio entre as regiões brasileiras e seus principais parceiros comerciais internacionais em 1999. Apontam que os estados brasileiros ainda se mostravam pouco integrados, tanto entre si quanto em relação ao comércio internacional. Contribuem significativamente para essa pequena integração comercial desigualdades produtivas e de renda no Brasil, aliados aos problemas de infraestrutura física e de transportes entre os estados.

Magalhães e Domingues (2007) aplicaram o modelo gravitacional a 31 grupos de atividades econômicas no intuito de captar os principais determinantes do comércio interestadual para cada classe de atividade analisada. No modelo utilizado, a variável dependente foi a pauta de exportações (vias internas) entre os estados. As variáveis independentes são os PIBs dos estados (representam os efeitos de oferta e a demanda), a distância entre as capitais dos estados (captura o efeito dos custos de transporte) e variáveis dummies (indicam fronteira comum entre estados e localização numa mesma macrorregião). Os resultados deste trabalho apontam que "as estruturas produtivas regionais no Brasil, em termos de sua renda e diversificação, mostram-se relacionadas com os fluxos de comércio entre os Estados" (MAGALHÃES; DOMINGUES, 2007, p. 16). Ademais, o trabalho revelou o quão importante é a articulação das regiões e dos estados em termos do mercado doméstico ao destacar que para todos os Estados, as vendas domésticas superaram, em diferentes magnitudes, as exportações internacionais.

Perobelli et al. (2006), através do método de Extração Hipotética aplicado a matriz inter-regional de insumo produto para o ano de 1996, e da análise dos efeitos para trás (backward effects) e efeitos para frente (forward effects), concluem que Norte, Nordeste e Centro-Oeste integram um grupo caracterizado por elevada dependência, no que tange à aquisição de insumos e vendas de produtos, do Sudeste e Sul. Em contrapartida, as regiões Sudeste e Sul formam um grupo 
caracterizado por possuírem alta interdependência regional e uma incipiente dependência em relação às demais regiões brasileiras.

Perobelli et al. (2008) buscam verificar a evolução das interdependências inter-regionais, dos setores agricultura e industrial sob a ótica do comércio intrasetorial (compras e vendas do setor agropecuário/industrial localizado em uma determinada unidade da Federação com relação ao mesmo setor localizado no restante do Brasil). O fazem também pela ótica do comércio intersetorial (interações entre a agricultura e/ou indústria de cada unidade da Federação, com relação, aos demais setores produtivos, localizados nas demais unidades da Federação). Aplicaram o método de Extração Hipotética em matrizes interestaduais de insumoproduto com base nos anos de 1996 e 2002, em conjunto a uma análise exploratória de dados espaciais ${ }^{4}$. Chegaram aos seguintes resultados: i) para a agricultura, sob a ótica das compras (backward effects), a maioria dos estados apresentou uma redução em seus níveis de dependência, no que concerne à aquisição e venda de produtos, tanto intra quanto intersetoriais, em relação ao restante do país. Todavia, tais alterações não se mostraram significativas ao ponto de alterar a estrutura produtiva existente, exceto Amazonas; ii) em relação às vendas da agricultura (forward effects), em 1996, houve um fluxo significativo de exportações proveniente da maioria das regiões. Porém, em 2002, esses fluxos diminuíram e se apresentaram mais estáveis, sob os dois aspectos analisados; iii) no que diz respeito às compras do setor industrial, para os efeitos intersetoriais, tem-se o alto grau de dependência da maioria dos estados da região Norte com relação à aquisição de insumos do restante do Brasil (estados importadores). Nas regiões Sudeste e Sul a dependência com relação ao restante do Brasil é bem menor. Quanto aos os efeitos do comércio intrasetorial tanto os backward effects quanto os forward effects diminuem para o período analisado em todas as regiões; iv) sob a ótica das vendas para a indústria, tanto inter como intrasetorial, destacou-se a relevante participação do estado de São Paulo, dado que o fluxo São Paulo - Brasil se mostrou mais expressivo que o inverso.

Resumindo os principais resultados dos trabalhos apresentados nesta seção, observa-se que até o final da década de 40 o sistema comercial brasileiro era "um arquipélago de ilhas econômicas isoladas. Apenas após a efetivação de um

\footnotetext{
${ }^{4}$ Neste trabalho os autores espacializam os resultados do método de extração aplicado à matriz de insumo-produto através do cálculo dos indicadores globais e locais de associação geográfica, para verificar o quanto a distância importa para os resultados de interações inter-regionais e intrarregionais.
} 
programa nacional de construção de rodovias, na década de 1950, é que se rompe com o estado de relativo isolamento das regiões.

Ademais, quanto ao padrão que se verifica a partir de 1985, nota-se a preponderância dos fluxos de comércio interestaduais associados às regiões mais desenvolvidas do país, Sul e Sudeste, em especial ao estado de São Paulo.

\section{Corrente de comércio inter-regional}

$\mathrm{Na}$ presente seção pretende-se sistematizar a distribuição da corrente de comércio regional para o país nos anos de 1998 e 2008, mediante a subdivisão desta em termos intrarregionais e transregionais, bem como verificar como se dá a integração comercial doméstica, através da análise do destino das exportações e origem das importações dos estados.

\section{Corrente de comércio total das regiões brasileiras}

Os dados revelam a existência de uma correlação negativa relativamente fraca (coeficiente de Pearson $=-0,1203$ ) entre a corrente de comércio das regiões brasileiras e o PIB per capita, as séries estão expostas no gráfico 01 . Isto implica que quanto maior o PIB per capita da região, menor tende a ser sua corrente de comércio total por vias interna.

É possível que a correlação em questão seja, porém, fundamentalmente afetada pelas peculiaridades que cercam duas das cinco regiões brasileiras. No caso da região Norte, é preciso levar em conta a presença da Zona Franca de Manaus, que aumenta substancialmente a corrente de comércio desta região. Já a região Sul apresenta a peculiaridade de ser fisicamente próxima aos países integrantes do Mercosul, o que também tende a aumentar substancialmente a corrente de comércio vis-à-vis outras regiões, nas quais a maior distância física acarreta custos de transporte que reduzem a viabilidade de maiores transações comerciais.

Gráfico 01: Corrente de comércio total das regiões brasileiras em relação aos respectivos PIBs regionais (\%) e PIB per capita das regiões brasileiras $(R \$)-1998$ e 2008 


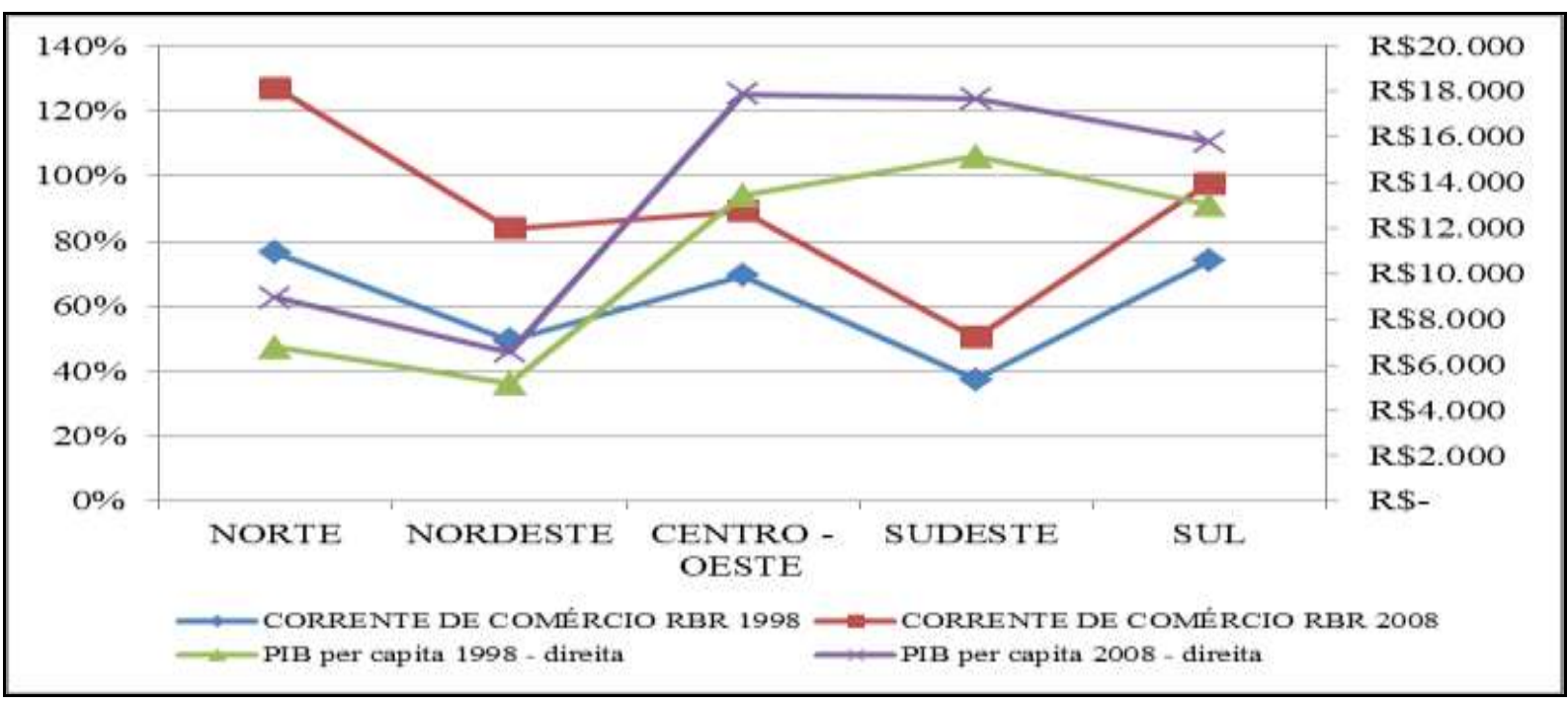

Fonte: Elaboração própria a partir de dados de Guilhoto et al. (2010), Vasconcellos (2001) e Vasconcellos e Oliveira (2006).

No comparativo entre os anos de 1998 e 2008, verifica-se a intensificação do comércio entre as regiões, dado que para todas as regiões observa-se o aumento da corrente de comércio/PIB. Por exemplo, em 2008 a corrente de comércio/PIB da região Norte está 50,61 p.p. maior que o observado em 1998.

A região que apresenta menor dependência em relação ao comércio com 0 restante do país no ano de 2008 é a região Sudeste. Em contrapartida, a região com maior dependência é a região Norte, cuja corrente de comércio total supera o próprio PIB em 26,99\%.

\section{Corrente de comércio intra e transregional para a região Norte}

Para a região Norte tem-se a existência de uma correlação positiva relativamente moderada (coeficiente de Pearson $=0,548$ ) entre a corrente de comércio intrarregional e o PIB per capita. Portanto, quanto maior o PIB per capita do estado pertencente a esta região, maior tende a ser sua participação no comércio regional. Em 2008, o estado que possui a maior proporção da corrente de comércio tanto trans como intrarregional em função de seu PIB é o Amazonas $(254,96 \%$ e $10,13 \%$, respectivamente), e o menor, para ambas as correntes de comércio, Roraima $(59,38 \%$ e 3,87\%). O coeficiente de correlação entre a corrente de comércio transregional em proporção ao PIB e o PIB per capita é positiva e relativamente moderada (coeficiente de Pearson $=0,506$ ) para a região Norte.

A discrepância das proporções em relação aos PIBs estaduais da corrente de comércio intrarregional e a corrente de comércio transregional, apresentadas na tabela 01, chama atenção para a existência de uma baixa integração comercial entre 
os estados da região Norte. Esses são dependentes do comércio praticado externamente a região, principalmente em relação a região Sudeste. Por exemplo, em 2008, a região Sudeste foi o destino de aproximadamente $57,14 \%$ das exportações dos estados da região Norte para os demais estados da região e do país. Ao somarmos todas as exportações dos estados da região Norte para o restante do país, em 2008, obtêm-se o total de 94,27\% das exportações dessa região, portanto, apenas 5,63\% das exportações da região representam o comércio entre seus estados membros. As importações apresentam o mesmo comportamento das exportações, posto que cerca de 95,13\% das importações nacionais dos estados nortenhos advinham das demais regiões do país.

\section{Corrente de comércio intra e transregional para a região Nordeste}

O estado que apresentou a maior corrente de comércio intrarregional em proporção ao respectivo PIB estadual para o Nordeste, em 1998, foi Sergipe $(51,18 \%)$, e o menor, Maranhão (16,30\%), tais informações também são observadas em 2008. Em contrapartida, a Bahia apresentou a maior corrente de comércio transregional em proporção ao PIB, tanto em 1998 (56,91\%) quanto em 2008 (135\%), enquanto, em 1998, o Piauí exibia o menor (39,75\%) e em 2008 a Paraiba $(83,46 \%)$. Os dados revelam a existência de uma correlação negativa relativamente fraca (coeficiente de Pearson $=-0,150$ ) entre a corrente de comércio intrarregional e - PIB per capita da região Nordeste. Ademais tem-se a existência de uma correlação positiva relativamente moderada (coeficiente de Pearson $=0,516$ ) entre a corrente de comércio transregional e o PIB per capita dos estados nordestinos.

As observações pertinentes a região Norte também são, de certa forma, relevantes para a região Nordeste, em menor grau. Há baixa integração comercial dos estados que a compõem, e dependência comercial em relação ao Sudeste, responsável, em 2008, por 45,57\% do total das exportações dos estados nordestinos para as demais regiões e estados membros da região, e 55,13\% das importações dos mesmos.

\section{Corrente de comércio intra e transregional para a região Centro-Oeste}

A circunscrição geográfica que possui a maior proporção da corrente de comércio intrarregional em função de seu PIB para a região Centro-Oeste, em 1998, é Mato Grosso (14,63\%), e em 2008, é Mato Grosso do Sul (11,15\%), e o menor, em ambos os anos, é o Distrito Federal. O coeficiente de correlação entre a corrente de 
comércio intrarregional em proporção ao PIB e o PIB per capita é negativo e extremamente forte (coeficiente de Pearson = -0,927). Mesmo se desconsiderarmos as externalidades provocadas pelo Distrito Federal, este indicador apresenta o valor de $-0,584$, o que implica relação inversa entre o comércio intrarregional e o PIB per capita.

Quanto ao coeficiente de correlação entre a corrente de comércio transregional em proporção ao PIB e o PIB per capita, o mesmo apresenta uma correlação negativa forte (coeficiente de Pearson $=-0,734$ ) para a região CentroOeste. Porém, ao desconsiderar-se a capital federal, tal coeficiente sobe para 0,846 (relação direta forte), denotando, portanto, a excepcionalidade do resultado.

No que tange a integração comercial, os estados do Centro-Oeste brasileiro, tal como as regiões analisadas anteriormente, apresentam baixa integração comercial regional. Do montante de exportações dos estados da região para os demais estados do país em 2008, apenas 9,80\% representam as exportações intrarregionais. No tocante as importações, apenas 7,32\% das mesmas representam trocas comerciais entre os estados do Centro-Oeste. Destaca-se ainda que a região Sudeste apresenta a maior participação relativa no destino das exportações e importações da região Centro-Oeste, a nível nacional, assim como para as regiões analisadas previamente.

\section{Corrente de comércio intra e transregional para a região Sudeste}

Para a região Sudeste os dados revelam a existência de uma correlação negativa relativamente forte (coeficiente de Pearson $=-0,762$ ) entre a corrente de comércio intrarregional e o PIB per capita - séries expostas na tabela 01 -. O estado que apresenta a maior corrente de comércio intrarregional em proporção ao seu PIB para o Sudeste, em 1998, foi o Espirito Santo (107,10\%), e o menor, São Paulo $(32,05 \%)$. No que concerne à proporção da corrente de comércio transregional/PIB, o maior foi São Paulo (46,26\%), e o menor, Rio de Janeiro (20,12\%). Tais considerações também vão de encontro ao observado em 2008. No tocante à correlação entre a corrente de comércio transregional/PIB e o PIB per capita, este é positiva e relativamente moderada (coeficiente de Pearson $=0,505$ ) para a região Sudeste.

Diferentemente das regiões apresentadas anteriormente, a região Sudeste apresenta maior integração comercial, dado que a maior parte das exportações e importações dos estados da região representam fluxos de comércio intrarregionais. 
Quanto aos fluxos de exportações e importações para as demais regiões do país destaca-se a região Sul, como destino (21,44\% das exportações) e origem $(21,87 \%$ das importações) da região Sudeste em relação as demais regiões do país em 2008.

\section{Corrente de comércio intra e transregional para a região Sul}

O coeficiente de correlação entre a corrente de comércio intrarregional em proporção ao PIB e o PIB per capita, para os estados da região Sul, apresenta uma correlação negativa extremamente fraca (coeficiente de Pearson = -0,019). Portanto, um maior PIB per capita dos estados sulinos não parece relacionar-se com o fluxo de comércio total do estado com os demais estados da região. O coeficiente de correlação entre a relação corrente de comércio transregional/PIB e o PIB per capita apresenta uma correlação positiva relativamente fraca (coeficiente de Pearson = 0,315).

A região Sul apresenta baixa integração comercial regional, dado que, por exemplo, em 2008 , a maior parte da pauta de exportações $(81,45 \%)$ e importações $(81,23 \%)$ da região, quando considerado o mercado interno, destina-se aos demais estados do país. Tais considerações se coadunam ao que ocorre com as regiões Norte, Nordeste e Centro-Oeste. Ademais, assim como em tais regiões, os estados sulinos apresentam pauta de exportações e importações fortemente atreladas a região Sudeste, responsável por $51,11 \%$ do destino das exportações da região Sul, e por $60,61 \%$ das suas importações.

Tabela 01: Coeficientes de Comércio Transregional e Intrarregional em relação ao PIB dos Estados Brasileiros em 1998 e 2008

\begin{tabular}{|c|c|c|c|c|c|c|}
\hline \multirow[t]{2}{*}{ UNIDADES DA FEDERAÇÃO } & \multicolumn{2}{|c|}{$\begin{array}{l}\text { Corrente de Comércio } \\
\text { Transregional/PIB (\%) }\end{array}$} & \multicolumn{2}{|c|}{$\begin{array}{l}\text { Corrente de Comércio } \\
\text { Intrarregional/PIB (\%) }\end{array}$} & \multicolumn{2}{|c|}{ PIB per capita $(\mathbf{R} \$)$} \\
\hline & 1998 & 2008 & 1998 & 2008 & 1998 & 2008 \\
\hline ACRE & 51,86 & 83,30 & 0,74 & 5,07 & $6.417,22$ & $9.108,12$ \\
\hline AMAPÁ & 43,79 & 82,34 & 5,82 & 4,90 & $7.463,00$ & $10.309,54$ \\
\hline AMAZONAS & 141,24 & 254,96 & 0,13 & 10,13 & $9.727,42$ & $11.373,64$ \\
\hline PARÁ & 45,30 & 149,35 & 1,04 & 5,13 & $6.103,80$ & $7.209,46$ \\
\hline RONDONIA & 57,69 & 116,00 & 0,17 & 9,56 & $6.752,38$ & $10.659,50$ \\
\hline RORAIMA & 33,35 & 59,38 & 0,14 & 3,87 & $9.216,02$ & $10.909,13$ \\
\hline TOCANTINS & 69,10 & 117,23 & 3,16 & 5,89 & $6.003,35$ & $9.290,57$ \\
\hline ALAGOAS & 40,55 & 93,73 & 44,17 & 24,69 & $4.901,90$ & $5.578,10$ \\
\hline BAHIA & 56,91 & 135,00 & 18,10 & 15,35 & $5.873,20$ & $7.267,80$ \\
\hline CEARÁ & 51,96 & 87,87 & 28,35 & 20,03 & $5.314,55$ & $6.241,21$ \\
\hline MARANHĀO & 42,21 & 119,42 & 16,30 & 15,14 & $3.562,51$ & $5.491,25$ \\
\hline PARAIBA & 40,35 & 83,46 & 44,48 & 24,85 & $4.278,06$ & $6.170,70$ \\
\hline PERNAMBUCO & 50,51 & 90,06 & 37,39 & 23,23 & $6.040,66$ & $6.883,17$ \\
\hline $\begin{array}{c}\text { PIAUI } \\
\end{array}$ & 39,75 & 96,79 & 35,55 & 21,49 & $3.612,50$ & $4.795,08$ \\
\hline RIO GRANDE DO NORTE & 40,62 & 87,20 & 30,26 & 22,88 & $6.052,62$ & 7213,59 \\
\hline SERGIPE & 44,03 & 94,83 & 51,18 & 26,12 & $6.728,68$ & $8.800,37$ \\
\hline
\end{tabular}




\begin{tabular}{c|c|c|c|c|c|c}
\hline DISTRITO FEDERAL & 28,90 & 59,25 & 4,21 & 5,03 & $35.704,00$ & $40.577,94$ \\
\hline GOIÁS & 98,37 & 138,20 & 11,11 & 10,56 & $8.868,60$ & $11.268,28$ \\
\hline MATO GROSSO & 115,69 & 159,91 & 10,86 & 9,95 & $8.949,46$ & $15.970,04$ \\
\hline MATO GROSSO DO SUL & 100,26 & 157,61 & 14,63 & 11,15 & $9.726,44$ & $11.940,71$ \\
\hline ESPIRITO SANTO & 27,99 & 87,33 & 107,10 & 80,14 & $11.949,11$ & $16.074,29$ \\
\hline MINAS GERAIS & 28,48 & 74,56 & 75,96 & 65,15 & $10.337,33$ & $12.360,38$ \\
\hline RIO DE JANEIRO & 20,12 & 66,80 & 52,16 & 54,50 & $16.219,77$ & $18.282,43$ \\
\hline SÁO PAULO & 46,26 & 93,51 & 32,05 & 32,38 & $18.035,31$ & $20.157,23$ \\
\hline PARANÁ & 98,39 & 144,06 & 33,24 & 21,65 & $11.432,11$ & $14.604,03$ \\
\hline RIO GRANDE DO SUL & 59,14 & 132,62 & 21,29 & 18,20 & $13.853,24$ & $15.870,76$ \\
\hline SANTA CATARINA & 67,13 & 123,13 & 47,11 & 30,31 & $15.415,32$ & $17.679,37$ \\
\hline
\end{tabular}

Fonte: Elaboração própria a partir de dados de Guilhoto et al. (2010), Vasconcellos (2001) e Vasconcellos e Oliveira (2006).

\section{Saldo da balança comercial e de serviços: regiões}

Nesta seção observa-se o saldo da balança comercial e de serviços das regiões brasileiras ponderados por seus respectivos PIBs. Ademais, tal como na seção anterior, realiza-se a subdivisão deste saldo em termos intrarregionais e transregionais e analisam-se os saldos de uma determinada região em relação às demais.

\section{Saldo geral}

No que concerne a análise do saldo geral da balança comercial e de serviços das regiões brasileiras em relação aos seus respectivos PIBs regionais, a região que apresenta o maior saldo, em 2008, é a região Sudeste (9,56\%), e a de menor saldo é a Nordeste (-25,65\%). Em ambos os anos, 1998 e 2008, as regiões Sudeste e Sul apresentam saldos gerais em proporção ao PIB positivos, o que sugere que as exportações dessas regiões são superiores às suas importações. As demais regiões apresentam saldos negativos.

Gráfico 02: Saldo geral da balança comercial e de serviços das regiões brasileiras em relação aos respectivos PIBs regionais (\%) e PIB per capita das regiões brasileiras $(R \$)$ - 1998 e 2008 


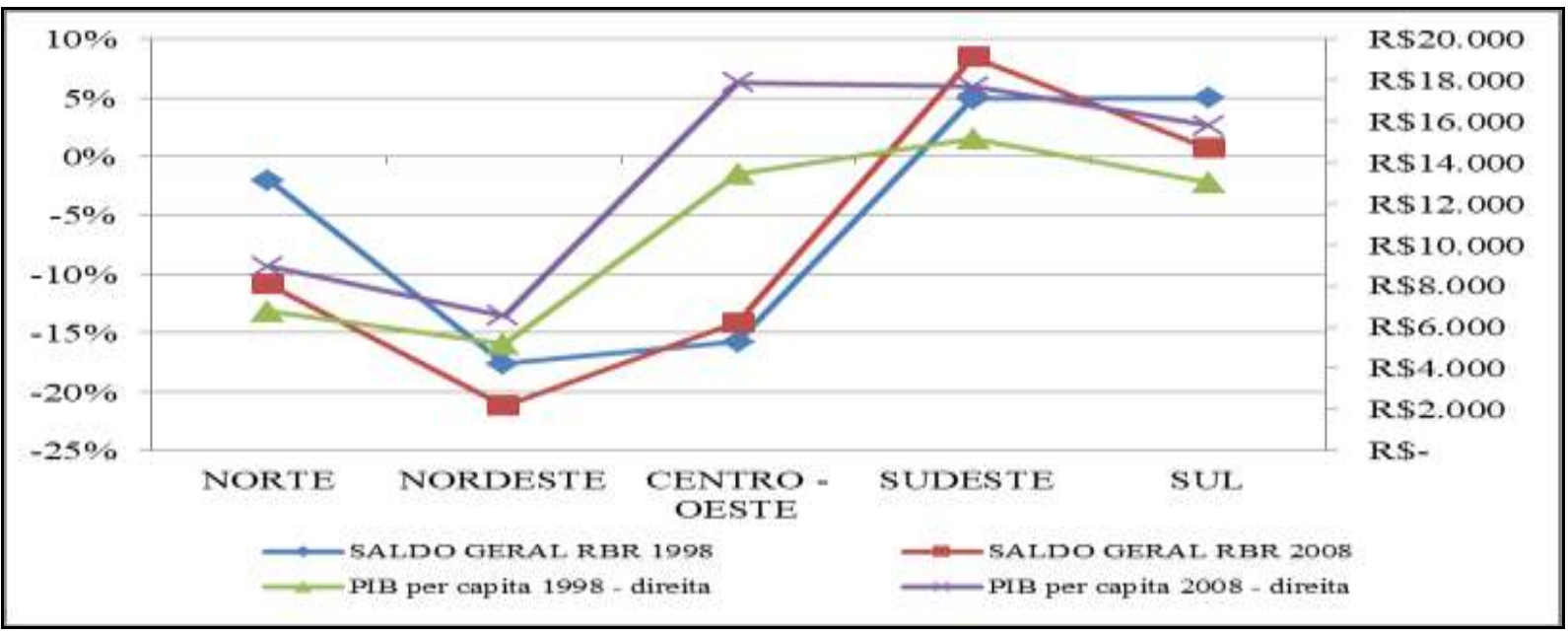

Fonte: Elaboração própria a partir de dados de Guilhoto et al. (2010), Vasconcellos (2001) e Vasconcellos e Oliveira (2006).

Ademais os dados revelam a existência de uma correlação positiva relativamente moderada (coeficiente de Pearson $=0,528$ ) entre as séries expostas no gráfico 02. Portanto, quanto maior é o PIB per capita da região, maior tende a ser seu saldo comercial e de serviços.

\section{Saldo comercial intra e transregional da região Norte}

No que concerne ao comércio intrarregional, apenas os estados do Amazonas, Rondônia e Tocantins apresentam saldos gerais em proporção ao PIB positivos em ambos os períodos. Acre e Amapá apresentam saldos positivos em 1998, enquanto os demais estados apresentam saldos negativos. Os dados revelam ainda a existência de uma correlação positiva relativamente fraca (coeficiente de Pearson $=0,111$ ) entre o saldo geral intrarregional dos estados da região Norte e o PIB per capita estadual.

Gráfico 03: Saldo geral intrarregional e transregional da balança comercial e de serviços dos estados da região Norte em relação aos respectivos PIBs estaduais (\%) -1998 e 2008 


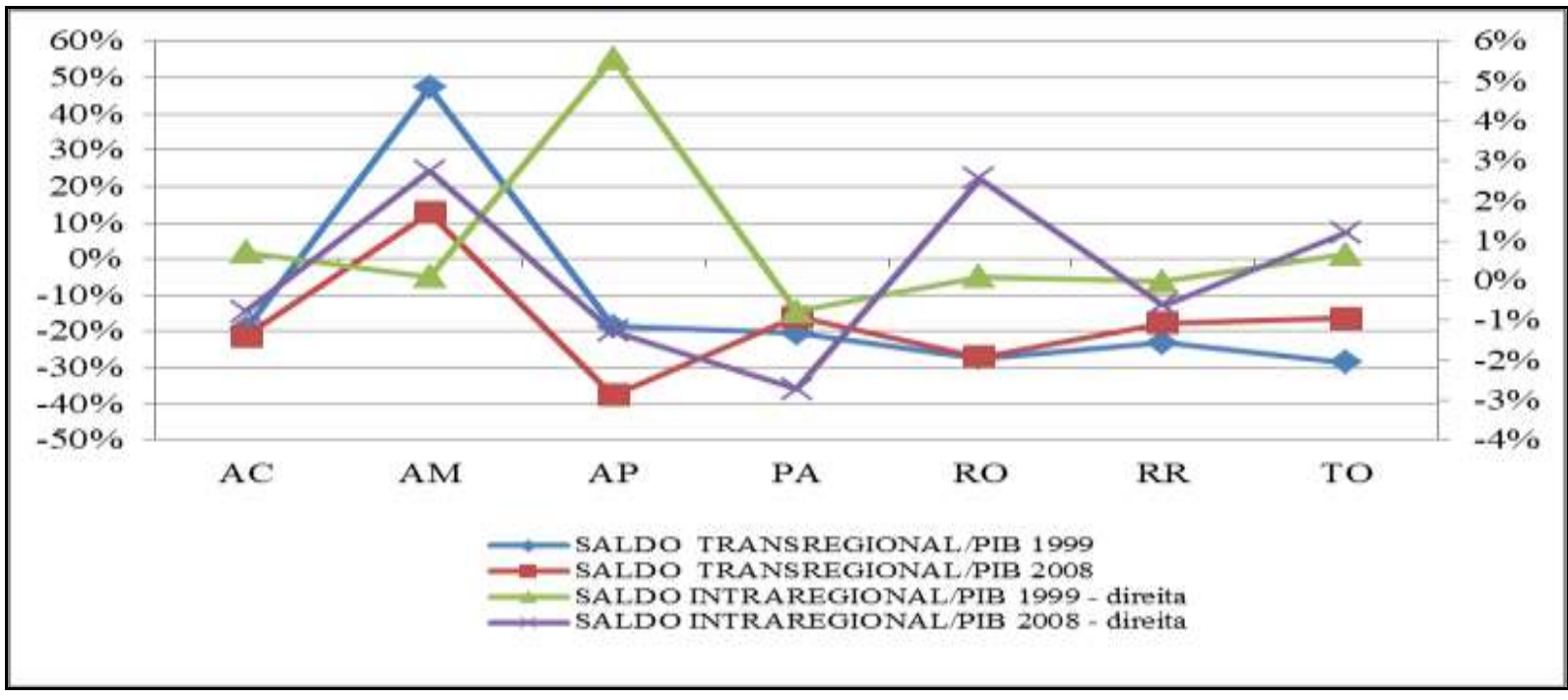

Fonte: Elaboração própria a partir de dados de Guilhoto et al. (2010), Vasconcellos (2001) e Vasconcellos e Oliveira (2006).

No que concerne ao saldo geral da balança comercial e de serviços transregional para os estados da Região Norte em relação aos seus respectivos PIBs estaduais, em 2008, o estado que apresenta o maior saldo é Amazonas (12,73\%), e o menor, Amapá (-37,59\%). Afora Amazonas, em ambos os anos, todos os demais estados apresentam saldos negativos. Há uma correlação positiva relativamente fraca (coeficiente de Pearson $=0,298$ ) entre 0 saldo geral transregional dos estados da região Norte e seus PIBs per capita.

Vale ainda atentar-se para o fato de que em conjunto os estados do Norte possuem saldo da balança comercial e de serviços superavitária apenas em relação aos do Nordeste, sendo o maior deficit em relação ao Sudeste, seguido pelo Sul.

\section{Saldo comercial intra e transregional da região Nordeste}

No que toca ao indicador saldo geral da balança comercial e de serviços intrarregional/PIB para os estados nordestinos, o maior, em 1998, é Pernambuco $(7,23 \%)$ e o menor, Sergipe (-16,59\%). Os dados revelam a existência de uma correlação positiva relativamente moderada (coeficiente de Pearson $=0,304$ ) entre esses saldos/PIB e os PIBs per capita estaduais.

Gráfico 04: Saldo geral intrarregional e transregional da balança comercial e de serviços dos estados da região Nordeste em relação aos respectivos PIBs estaduais (\%) - 1998 e 2008 


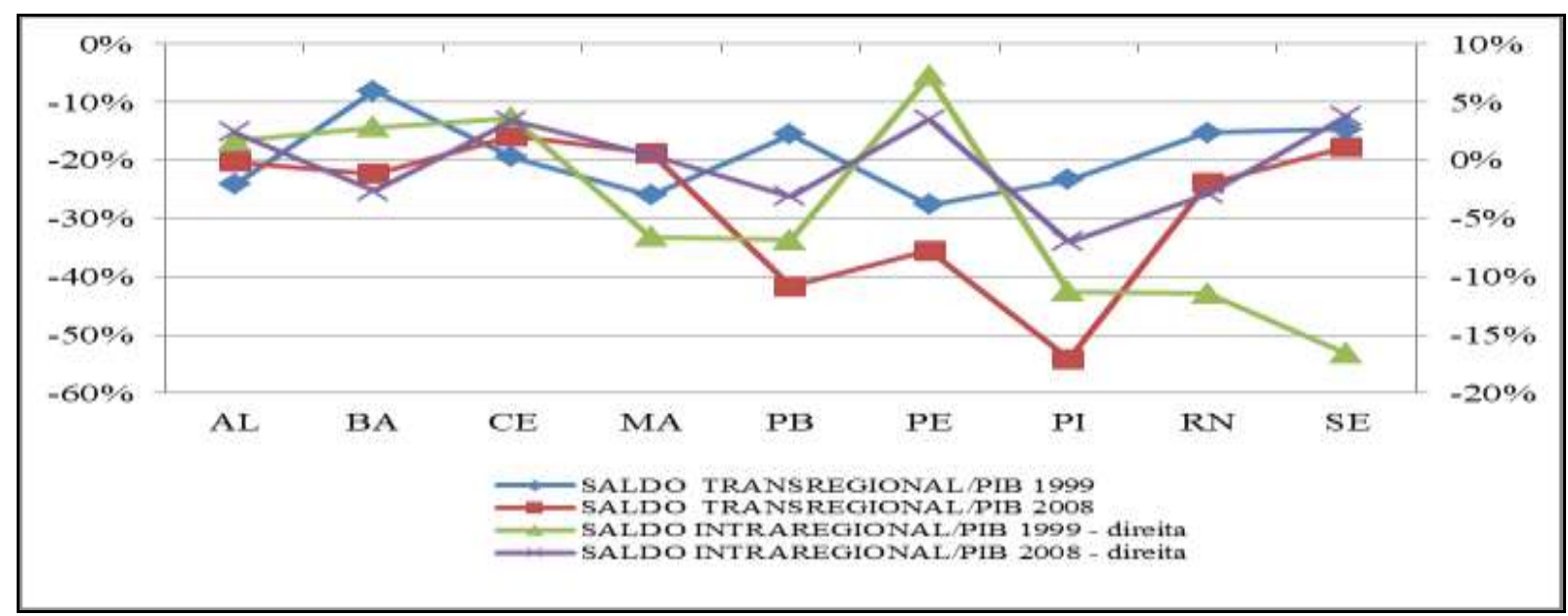

Fonte: Elaboração própria a partir de dados de Guilhoto et al. (2010), Vasconcellos (2001) e Vasconcellos e Oliveira (2006).

Em 2008, o estado que apresenta o maior saldo transregional é o Ceará ($15,87 \%)$, e o menor é o Piauí (-54,12\%). Todos os estados da região apresentam este indicador deficitário, tanto em 1998 quanto em 2008. O coeficiente de Pearson $(=0,135)$ revelou correlação positiva relativamente fraca entre os saldos/PIB transregionais e os PIBs per capita estaduais.

O Nordeste brasileiro mantém uma relação deficitária com as demais regiões do país, e individualmente todos os estados também apresentam saldos deficitários. Quanto ao déficit em relação às demais regiões, destaca-se o elevado déficit da região Nordeste em relação à região Sudeste ( $\mathrm{R} \$ 54,4$ bilhões em 2008).

\section{Saldo comercial intra e transregional da região Centro-Oeste}

No que concerne à análise do saldo geral da balança comercial e de serviços intrarregional/PIB para os estados da Região Centro-Oeste, em 1998, o maior saldo é de Goiás (2,38\%) - único estado superavitário intrarregionalmente em 1998 -, e o menor Mato Grosso (-1,28\%). Em 2008, Goiás e Mato Grosso apresentam superavits, e os demais estados, deficits. O coeficiente de Pearson $(-0,409)$ revela correlação negativa relativamente moderada entre os saldos intrarregionais/PIB dos estados dessa região e seus respectivos PIBs per capita.

Quanto ao saldo transregional/PIB, em 2008, o maior é o do Mato Grosso (24,64\%), e o menor é o do Distrito Federal $(-31,22 \%)$. Com exceção do Mato Grosso (e apenas em 2008), todos os demais estados da região apresentam saldos transregionais deficitários. Há correlação negativa relativamente moderada (coeficiente de Pearson $=-0,453$ ) entre os saldos transregionais dos estados e seus PIBs per capita. 
Gráfico 05: Saldo geral intrarregional e transregional da balança comercial e de serviços dos estados da região Centro-Oeste em relação aos respectivos PIBs estaduais (\%) - 1998 e 2008

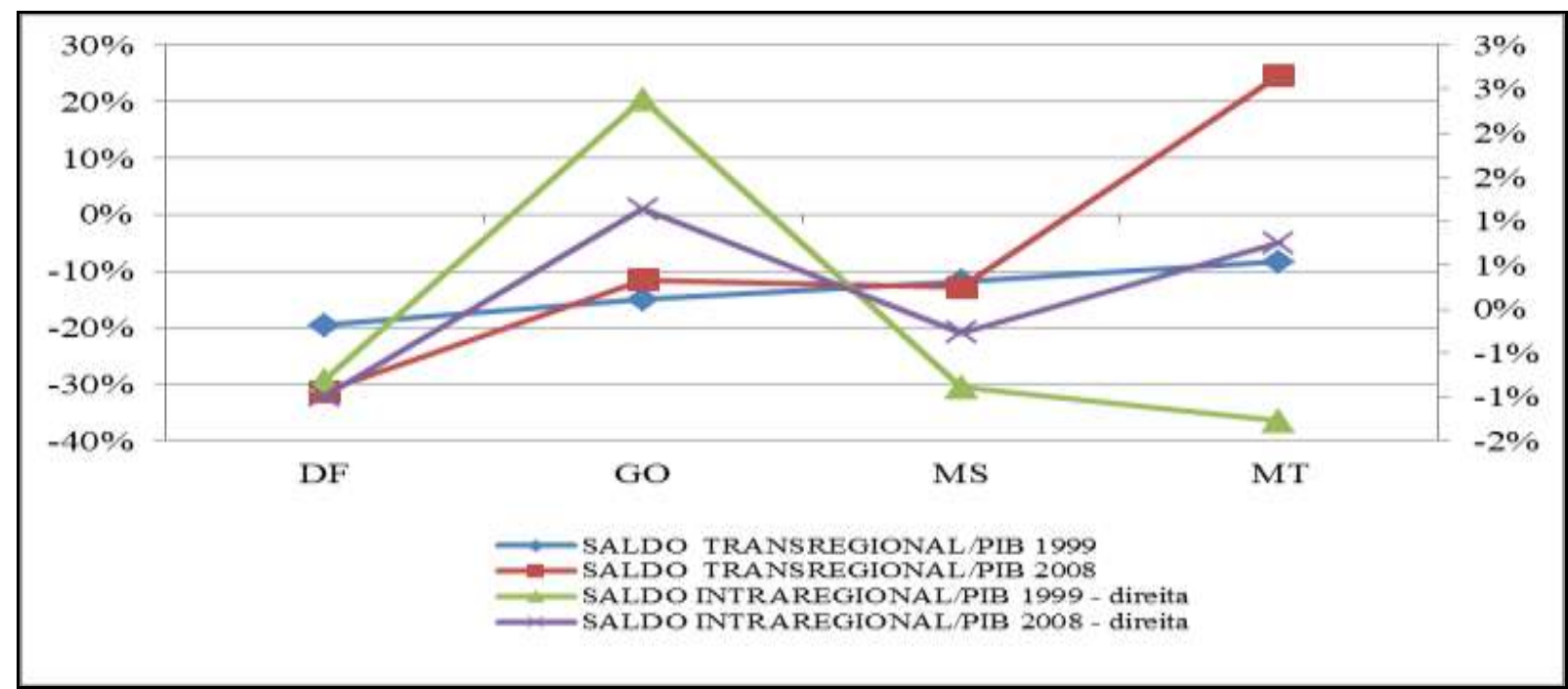

Fonte: Elaboração própria a partir de dados de Guilhoto et al. (2010), Vasconcellos (2001) e Vasconcellos e Oliveira (2006).

Observando-se o saldo da balança comercial e de serviços dos estados da região Centro Oeste em conjunto, em relação às demais regiões do país, notam-se superavits em relação ao Norte e ao Nordeste, e deficits com o Sul e, principalmente, o Sudeste.

\section{Saldo comercial intra e transregional da região Sudeste}

A partir da análise do saldo geral da balança comercial e de serviços intrarregional para os estados da Região Sudeste em relação aos seus respectivos PIBs estaduais, infere-se que, em ambos os anos analisados o maior saldo é de São Paulo (2,57\% em 1998 e 6,82\% em 2008). O menor em 1998 é o Rio de Janeiro (8,35\%), e em 2008 Minas Gerais (-10,29\%). Exceto São Paulo, em 2008, todos os demais estados da região apresentam saldos negativos. Há correlação positiva relativamente baixa (coeficiente de Pearson $=0,107$ ) entre o saldo geral da balança 
comercial e de serviços intrarregional dos estados da região Sudeste e seus respectivos PIBs per capitas.

Gráfico 06: Saldo geral intrarregional e transregional da balança comercial e de serviços dos estados da região Sudeste em relação aos respectivos PIBs estaduais (\%) -1998 e 2008

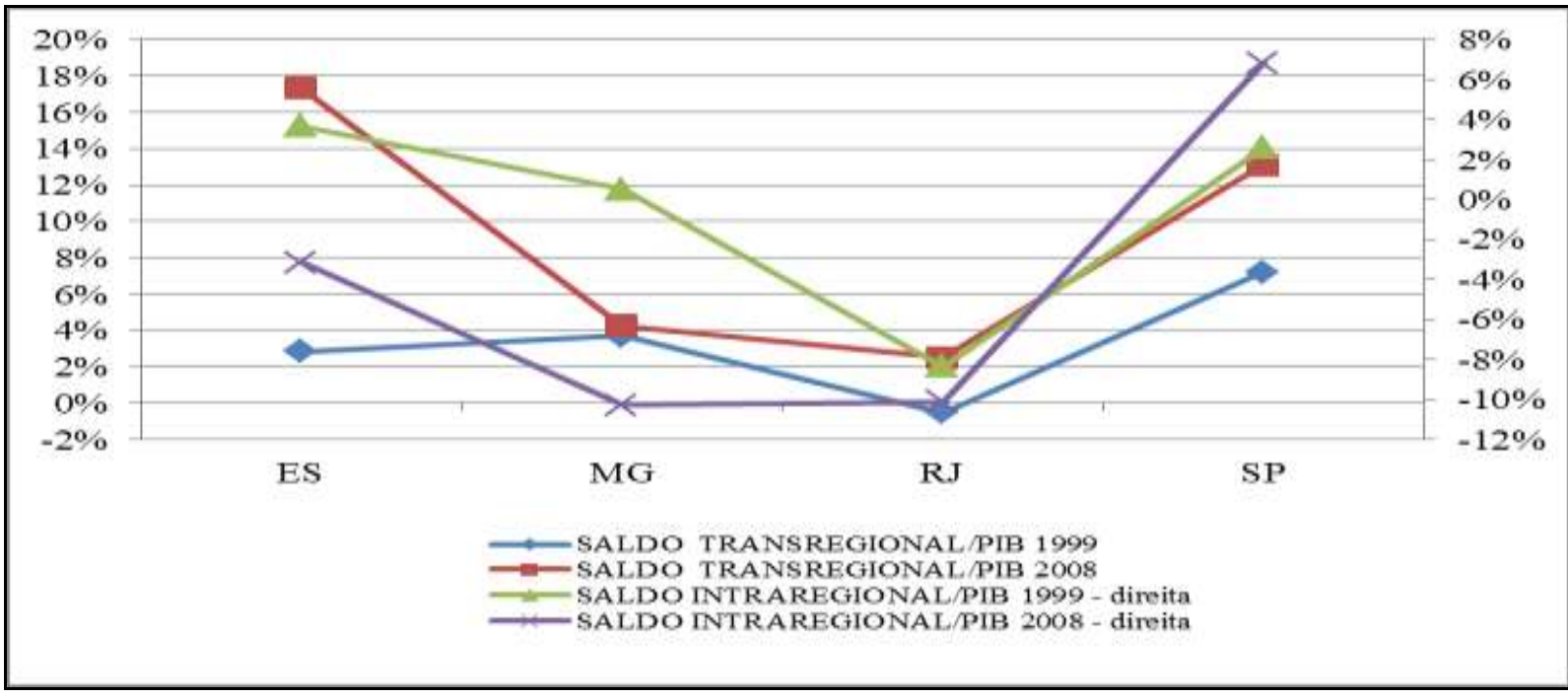

Fonte: Elaboração própria a partir de dados de Guilhoto et al. (2010), Vasconcellos (2001) e Vasconcellos e Oliveira (2006).

Em relação à razão saldo transregional/PIB dos estados dessa Região, o maior saldo, em 1998, é o de São Paulo (7,21\%), e, em 2008, o do Espírito Santo (17,32\%). O menor saldo, em ambos os períodos, é o do Rio de Janeiro (-0,53\% em 1998 e 2,49\% em 2008). Exceto o Rio de Janeiro em 1998 (-0,53\%), todos os estados da região Sudeste apresentam saldos transregionais positivos, e o coeficiente de Pearson $(0,387)$ mostra correlação positiva relativamente fraca entre os saldos transregionais/PIB dos estados da região e seus respectivos PIBs per capita.

\section{Saldo comercial intra e transregional da região Sul}

Em 2008, a maior relação saldo geral da balança comercial e de serviços intrarregional/PIB dos estados da Região Sul é de Santa Catarina (2,70\%), e o menor, do Rio Grande do Sul (-2,17\%). Em 1998 apenas o estado do Paraná apresenta saldo intrarregional positivo, enquanto em 2008 apenas o Rio Grande do Sul é negativo. Há correlação negativa relativamente moderada (coeficiente de Pearson $=0,381$ ) entre os saldos intrarregionais/PIB e os PIBs per capita dos estados meridionais. 
Gráfico 07: Saldo geral intrarregional e transregional da balança comercial e de serviços dos estados da região Sul em relação aos respectivos PIBs estaduais (\%) 1998 e 2008

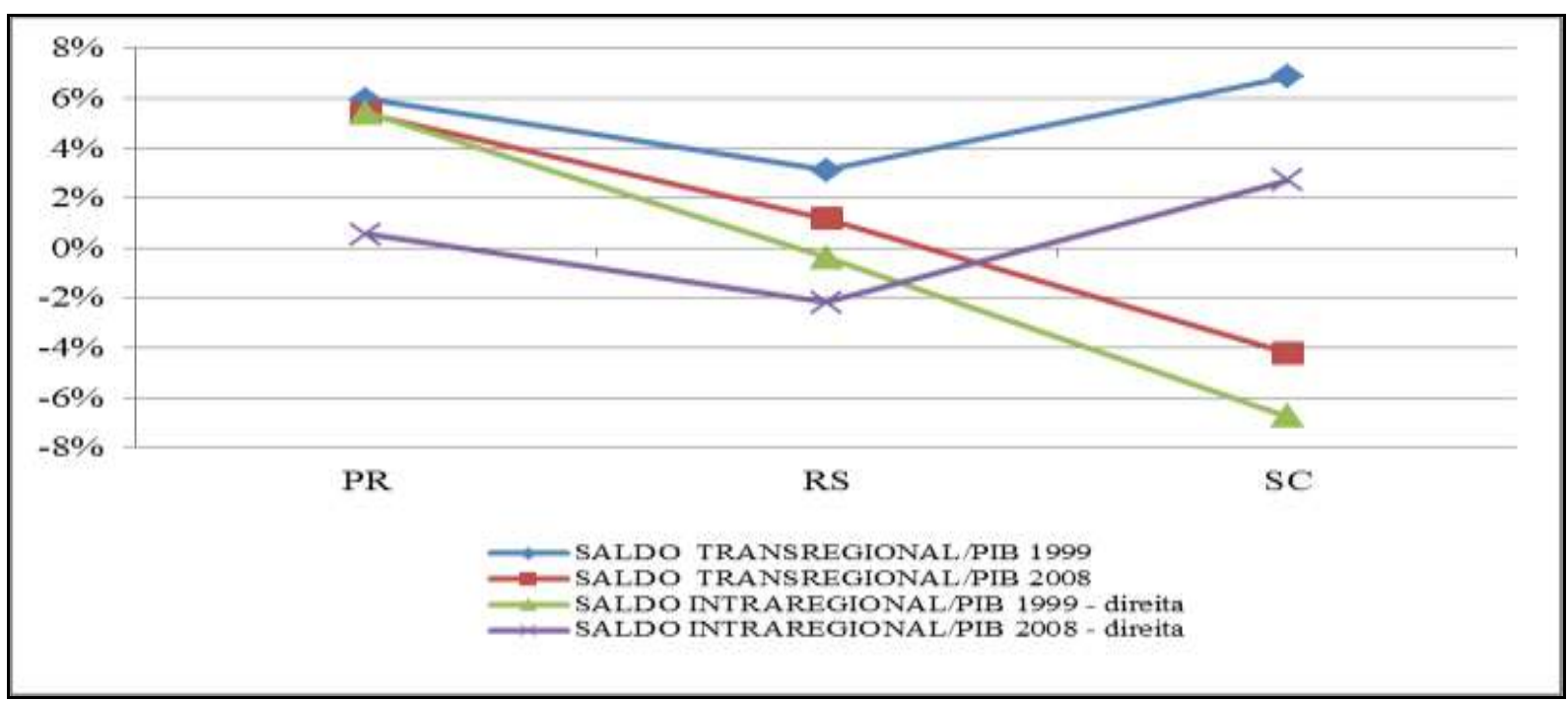

Fonte: Elaboração própria a partir de dados de Guilhoto et al. (2010), Vasconcellos (2001) e Vasconcellos e Oliveira (2006).

Quanto à razão saldo transregional/PIB dos estados da Região, em 1998, o menor saldo é o do Rio Grande do Sul (3,12\%), e o maior, o de Santa Catarina (6,87\%). Em 2008, Paraná e Rio Grande do Sul apresentam-se superavitários, e Santa Catarina, deficitária. O coeficiente de Pearson $(-0,714)$ revela correlação negativa relativamente forte entre a razão saldos transregionais/PIB e os PIBs per capita desses estados.

Cabe ainda ressaltar que a região Sul é deficitária em relação ao Sudeste, e superavitária em relação às demais regiões do país.

\section{Modelo econométrico}

Como ressaltado na introdução, na quarta seção verifica-se como os fluxos de comércio relacionam-se com os níveis de renda e renda per capita estadual mediante a estimação de modelos de dados em painel.

\section{Base de dados}

Para a estimação dos modelos propostos, serão utilizados dados provenientes do trabalho de Vasconcelos (2001) e Vasconcelos e Oliveira (2006) fluxos de comércio interestaduais para os anos de 1998 e 1999 - da Diretoria de Estudos Regionais e Urbanos (DIRUR) do IPEA. Tais trabalhos tiveram como base a 
análise da matriz por atividade econômica do comércio interestadual. A partir da estimação das matrizes de insumo-produto (MIPs) para os vinte e seis estados brasileiros e o Distrito Federal empreendida por Guilhoto et al. (2010), foi possível obter os fluxos de comércio para o ano de 2008.

Quadro 01: Definição e Fontes das Variáveis

\begin{tabular}{|c|c|c|c|c|}
\hline Variável & Descrição & Fonte de dados & Período & $\begin{array}{c}\text { № de } \\
\text { observações }\end{array}$ \\
\hline CCT & $\begin{array}{c}\text { Corrente de Comércio } \\
\text { Transregional }\end{array}$ & \multirow{2}{*}{$\begin{array}{c}\text { Vasconcelos (2001), } \\
\text { Vasconcelos e Oliveira } \\
\text { (2006) e Guilhoto et al. } \\
(2010)\end{array}$} & $\begin{array}{l}1998,1999 \\
\text { e } 2008\end{array}$ & 81 \\
\hline $\mathrm{CCl}$ & $\begin{array}{c}\text { Corrente de Comércio } \\
\text { Intrarregional }\end{array}$ & & $\begin{array}{l}1998,1999 \\
\text { e } 2008\end{array}$ & 81 \\
\hline PIB & Produto Interno Bruto Estadual & \multirow{2}{*}{$\begin{array}{l}\text { Contas Regio-nais/IBGE e } \\
\text { Guilhoto et al. (2010) }\end{array}$} & $\begin{array}{l}1998,1999 \\
\text { e } 2008\end{array}$ & 81 \\
\hline PIBpercapita & $\begin{array}{l}\text { Produto Interno Bruto per } \\
\text { capita Estadual }\end{array}$ & & $\begin{array}{l}1998,1999 \\
\text { e } 2008\end{array}$ & 81 \\
\hline
\end{tabular}

Fonte: Elaboração própria dos autores.

No que concerne ao PIB e PIB per capita estaduais, para os anos de 1998 e 1999, estes foram obtidos a partir de dados das contas regionais disponibilizadas pelo IBGE. Para o ano de 2008 o PIB foi oriundo das MIPs e a população estadual/regional das contas regionais.

Para evitar eventuais distorções entre os distintos momentos em que os dados foram analisados, os mesmos foram deflacionados através do IGP - FGV, R\$ de 2004 - ano base das MIPs.

\section{Estatísticas descritivas}

O quadro 02 mostra um resumo das variáveis utilizadas de acordo com a terminologia do quadro 01:

Quadro 02: Resumo das estatísticas descritivas das variáveis

\begin{tabular}{|l|c|c|c|c|}
\hline \multicolumn{1}{|c|}{ Variável } & Média & Máxima & Mínima & $\begin{array}{c}\text { Coeficiente de } \\
\text { variação }\end{array}$ \\
\hline CCT/PIB & 0,757 & 2,54 & 0,188 & 0,568 \\
\hline CCI/PIB & 0,255 & 1,20 & 0,0013 & 0,932 \\
\hline PIB $^{\star}$ & $78.005,9$ & $826.680,9$ & $2.402,7$ & 1,768 \\
\hline PIBpercapita $^{\star \star}$ & $10.340,1$ & $40.577,9$ & $3.562,5$ & 0,652 \\
\hline
\end{tabular}

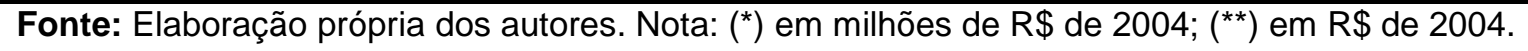

Como se observa do quadro acima, a média para a razão CCT/PIB, para o conjunto de dados analisados, é de 75,7\%, patamar este superior à média 
observada no biênio 1998-1999 (58,24\%) e menor que o verificado em 2008 $(110,66 \%)$. Isso denota a crescente importância relativa do comércio transregional no produto dos estados. O valor máximo da CCT/PIB corresponde ao estado do Amazonas em 2008, enquanto Rondônia detém o menor índice (18,8\% em 1999).

Com relação à $\mathrm{CCI} / \mathrm{PIB}$, é interessante observar a sua reduzida magnitude (média de $25,5 \%$ ), em relação à razão CCT/PIB. No tocante a esta variável verificase um movimento oposto ao observado para a corrente transregional, dado que sua média em 2008 (21,38\%) é menor que a notada no biênio 1998-1999 (27,61\%). Seu valor máximo corresponde ao estado do Espírito Santo (120\% em 1999), e o menor o estado do Amazonas, apenas 0,13\% em 1998.

Quanto ao PIB, cabe notar o elevado valor do coeficiente de variação para esta variável $(1,768)$, bem superior aos demais, evidenciando a grande variabilidade de desempenho econômico dentro do país. No tocante ao PIB per capita seu valor máximo corresponde ao Distrito Federal em 2008 e o mínimo ao Maranhão em 1998.

\section{Modelagem}

A metodologia consistiu em estimar modelos de dados em painel ${ }^{5}$ não espacial desbalanceado que relacionam tais variáveis, usando-se os dados de corte para os vinte e seis estados brasileiros e o Distrito Federal.

A fim de se verificar qual modelo melhor adequa-se ao conjunto de dados disponíveis, estimaram-se modelos ${ }^{6}$ do tipo lin-lin, lin-log, log-lin e $\log -\log$ relacionando as variáveis a serem mensuradas entre $\mathrm{si}$, e com os demais regressores, PIB e PIB per capita. Ao fim desse processo, optou-se por trabalhar com os modelos na forma log-log. Assim, formalmente, tem-se:

$$
\begin{aligned}
& \ln C C T=\beta_{0}+\beta_{1} \ln P I B+\beta_{2} \ln P I B \text { percapita }+u_{i} \\
& \ln C C I=\beta_{0}+\beta_{1} \ln P I B+\beta_{2} \ln P I B \text { percapita }+u_{i}
\end{aligned}
$$

No intuito de decidir entre os modelos de dados em painel, executou-se uma série de testes. Inicialmente, realiza-se o teste de $\mathrm{Chow}^{7}$ para verificar-se se a forma

\footnotetext{
${ }^{5}$ Vide Wooldridge (2002).

6 Para cada tipo de modelo estimou-se a relação entre os fluxos comerciais e cada variável explicativa de forma individual e em conjunto, totalizando 672 modelos estimados.

${ }^{7}$ Através do teste de Chow, a amostra é dividida em dois grupos no intuito de verificar-se a consistência dos parâmetros nas duas amostras. Mudanças significativas entre os parâmetros estimados acarretam em uma quebra estrutural dos dados, portanto, o modelo pooled não é adequado.
} 
mais simples da análise de dados em painel, pooled, é adequada quando comparada ao método de efeitos fixos (EF). Em seguida, realiza-se, através do teste LM de Breusch-Pagan ${ }^{8}$, a adequação do modelo pooled frente ao método de efeitos aleatórios (EA). Por fim, para a tomada de decisão entre EF e EA, executou-se o teste de Hausman ${ }^{9}$. A hipótese nula subjacente ao teste de Hausman é a de que os estimadores por EA são adequados. Se a hipótese nula for rejeitada, o modelo de EA não é adequado, pois os efeitos aleatórios provavelmente estão correlacionados com um ou mais regressores. Nesse caso, o modelo por EF é preferível ao por EA.

Tomada à decisão quanto ao tipo de modelo (pooled, EF ou EA) preferível, se faz necessário à realização de testes que verifiquem os pressupostos da regressão. Isto é, para os modelos testados foi verificada a presença de normalidade dos resíduos, heterocedasticidade e autocorrelação.

\section{Resultados estimados}

\section{Corrente de comércio transregional}

Para a corrente de comércio transregional o método de estimação por EF mostrou-se o mais adequado ao conjunto de dados disponíveis. Nesse caso, foram rejeitadas as hipóteses nulas do teste de Chow e de Breusch-Pagan, o que indica que o modelo pooled não é adequado. No tocante ao teste de Hausman, sua estatística de teste ( $p$-valor) foi menor que 5\%, portanto rejeita-se a hipótese nula de que os estimadores por EA são consistentes.

Quadro 03: Resultados dos testes de especificação do modelo

\begin{tabular}{|l|c|}
\hline \multicolumn{1}{|c|}{ TESTES } & $\boldsymbol{p}$-valor \\
\hline Teste de Chow & 0,000102695 \\
\hline Teste de Breusch-Pagan & 0,00117266 \\
\hline Teste de Hausman & $2,51836 \mathrm{e}-020$ \\
\hline
\end{tabular}

Fonte: Elaboração própria dos autores.

Em relação aos pressupostos básicos do modelo, isto é, normalidade dos resíduos, homocedasticidade e ausência de autocorrelação, foram utilizados, respectivamente, os seguintes testes que verificam a ocorrência de tais pressupostos: Jarque Bera; teste de Wald, e; o teste de Durbin-Watson. O quadro 04 abaixo sintetiza os resultados auferidos nesses testes.

\footnotetext{
${ }^{8} \mathrm{~A}$ hipótese nula do teste de Breusch-Pagan é que a variância do termo do erro do intercepto é constante. Se essa variância for constante não há diferença entre os modelos, e pode-se utilizar o modelo pooled. Se a hipótese nula for rejeitada, o modelo mais adequado é de efeitos aleatórios.

${ }^{9}$ Ver Gujarati e Porter (2011, p. 600-601).
} 
Quadro 04: Resultados dos testes de especificação em relação aos pressupostos básicos do modelo de regressão

\begin{tabular}{|l|c|}
\hline \multicolumn{1}{|c|}{ TESTES } & $\boldsymbol{p}$-valor \\
\hline Teste de Jarque Bera & 0,00366 \\
\hline Teste de Wald & 0,0000 \\
\hline Teste de Durbin-Watson & 0,267489 \\
\hline
\end{tabular}

Fonte: Elaboração própria dos autores.

Conforme verificado no quadro 04 os dados apresentaram problemas de normalidade dos resíduos e heterocedasticidade. Diante da quebra de tais pressupostos foram utilizados os estimadores de mínimos quadrados ponderados. 0 método atribui menor peso para as observações com maior variância do erro. Enquanto, o método MQO dá a todas as observações o mesmo peso, por isso ele é adequado quando a variância do erro é constante.

Nesse caso, a tabela abaixo sintetiza os resultados econométricos auferidos para o modelo que apresentou o melhor ajuste estatístico para a corrente de comércio transregional.

Tabela 02: Resultados para a corrente de comércio transregional

\begin{tabular}{ccccc}
\hline \multicolumn{5}{c}{ Modelo: Mínimos Quadrados Ponderados. Variável dependente: logCCTRANSREGIONAL } \\
\hline & Coeficiente & Erro Padrão & razão-t & p-valor \\
Const. & $-2,670$ & 0,886 & $-3,012$ & $0,0035^{* * *}$ \\
logPIB & 1,079 & 0,0398 & 27,09 & $1,97 e-041^{* * *}$ \\
logPIBpercap. & 0,159 & 0,113 & 1,4 & 0,1655 \\
\hline R-quadrado & 0,9297 & & R-quadrado ajustado & 0,9279 \\
F(2,78) & 515,86 & & P-valor (F) & $1,07 \mathrm{E}-45$ \\
Log da & $-113,23$ & Critério de Akaike & 232,45 \\
verossimilhança & 239,63 & $\begin{array}{l}\text { Critério Hannan- } \\
\text { Quinn }\end{array}$ \\
Critério de Schwarz & & & 235,33
\end{tabular}

Fonte: Elaboração própria dos autores. Nota: $\left(^{*}\right)$ parâmetros estatisticamente significantes a 10\%; $\left({ }^{* *}\right)$ parâmetros estatisticamente significantes a $5 \% ;\left(^{\star * *}\right)$ parâmetros estatisticamente significantes a $1 \%$. 
Os resultados indicam uma boa aderência do modelo aos dados, vez que a estatística-F é significativa a $1 \%$ e o R-quadrado do modelo foi de 0,9297, demonstrando um ótimo percentual de significância. Captou-se uma relação positiva entre a corrente de comércio transregional e o produto regional bruto. Nesse caso, a elasticidade da corrente de comércio transregional em relação ao produto é de 1,079 , indicando que o aumento de um ponto percentual no produto regional bruto eleva a corrente de comércio transregional em 1,079 pontos percentuais.

No tocante à relação entre a corrente de comércio transregional e o PIB per capita captou-se uma relação positiva, todavia, estatisticamente insignificante.

Convém agora verificar-se, quando consideramos as regiões individualmente, a influência do PIB e do PIB per capita sobre sua respectiva corrente de comércio transregional. Tais informações estão contidas na tabela 03.

Tabela 03: Resultados para a corrente de comércio transregional por região Modelo: Mínimos Quadrados Ponderados. Corrente de Comércio Transregional por Região

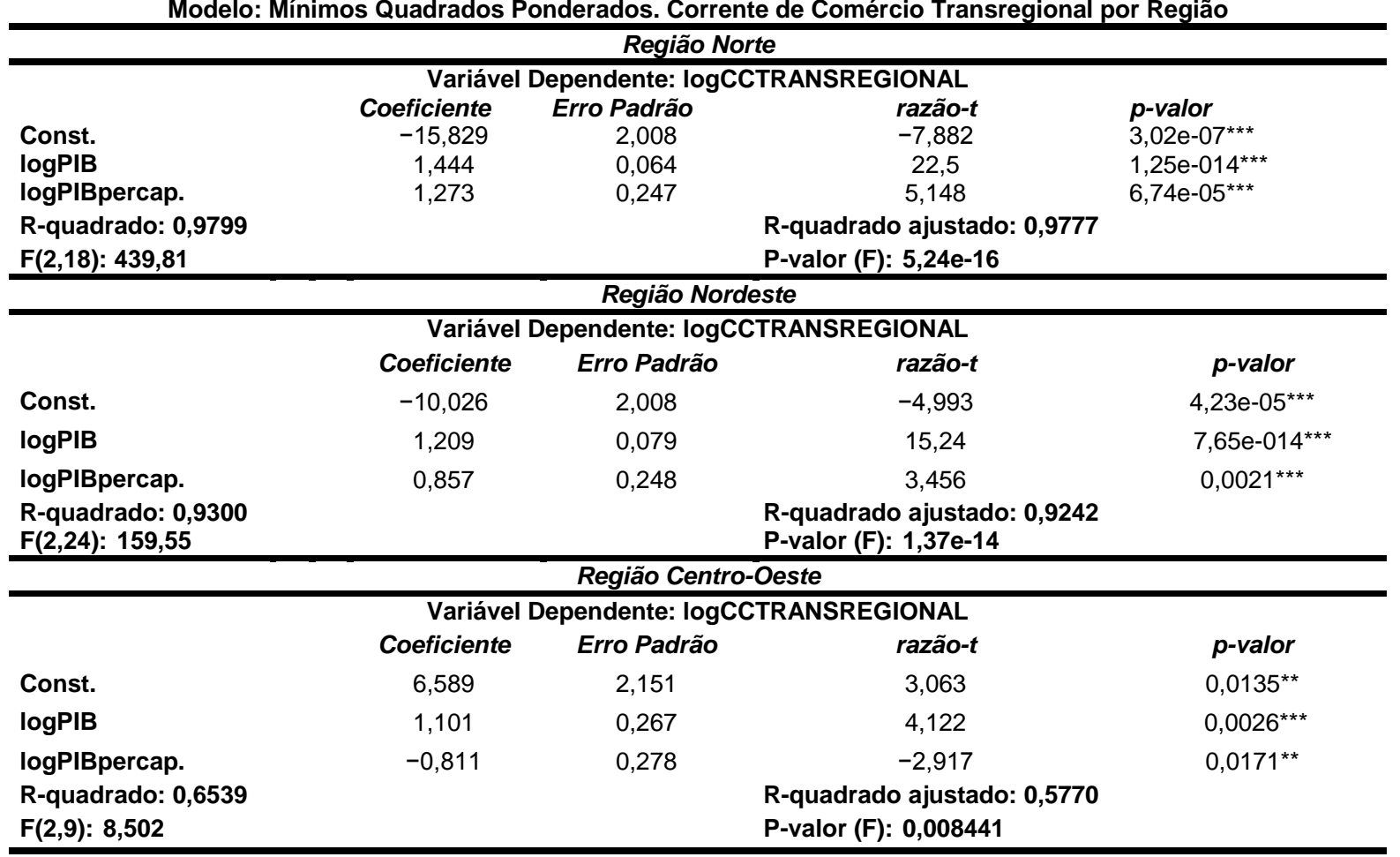

Região Sudeste

\begin{tabular}{lcccc}
\hline \multicolumn{4}{c}{ Região Sudeste } \\
\hline & \multicolumn{4}{c}{ Variável Dependente: logCCTRANSREGIONAL } \\
Coeficiente & Erro Padrão & razão-t & $\boldsymbol{p}$-valor \\
Const. & $-12,572$ & 5,833 & $-2,155$ & $0,0595^{*}$ \\
logPIB & 1,03 & 0,157 & 6,575 & $0,0001^{* * *}$
\end{tabular}




\begin{tabular}{|c|c|c|c|c|}
\hline $\begin{array}{l}\text { logPIBpcap. } \\
\text { R-quadrado: } 0,9322 \\
\text { F(2,9): } 61,893\end{array}$ & 1,19 & 0,733 & $\begin{array}{l}1,625 \\
\text { R-quadrado ajustado: } 0,9172 \\
\text { P-valor (F): } 5,49 \mathrm{e}-06\end{array}$ & 0,1387 \\
\hline \multicolumn{5}{|c|}{ Região Sul } \\
\hline \multicolumn{5}{|c|}{ Variável Dependente: logCCTRANSREGIONAL } \\
\hline & Coeficiente & Erro Padrão & razão-t & p-valor \\
\hline Const. & $-11,968$ & 7,825 & $-1,529$ & 0,177 \\
\hline $\log P I B$ & 1,792 & 0,364 & 4,925 & $0,0026^{* * *}$ \\
\hline logPIBpercap. & 0,287 & 0,626 & 0,458 & 0,6629 \\
\hline $\begin{array}{l}\text { R-quadrado: } 0,8022 \\
F(2,6): 12,165\end{array}$ & & & $\begin{array}{l}\text { R-quadrado ajustado: } 0,7362 \\
\text { P-valor (F): } 0,007742\end{array}$ & \\
\hline
\end{tabular}

Fonte: Elaboração própria dos autores. Nota: $\left(^{*}\right)$ parâmetros estatisticamente significantes a $10 \% ;\left(^{* *}\right)$ parâmetros estatisticamente significantes a $\left.5 \% ;{ }^{* * *}\right)$ parâmetros estatisticamente significantes a $1 \%$.

Para a região Norte tem-se uma relação positiva entre a corrente de comércio transregional, o PIB e o PIB per capita, portanto, maiores níveis de renda per capita da região estão relacionados com uma maior participação do comércio transregional na pauta de exportações e importações dos estados que compõem tal região.

Quanto à região Nordeste, captou-se a relação positiva de sua corrente de comércio transregional e o PIB. Nesse caso, tem-se que o aumento de um ponto percentual no produto regional bruto eleva a corrente de comércio transregional da região em 1,209 pontos percentuais. No que tange ao PIB per capita da região também captou-se uma relação positiva desta variável com a corrente de comércio transregional da região ao indicar-se que o aumento de um ponto percentual no PIB per capita da região eleva sua corrente de comércio transregional em 0,857 pontos percentuais.

Diferentemente do observado para o Norte e Nordeste, captou-se uma relação inversa entre a corrente de comércio transregional e o PIB per capita da região Centro-Oeste. A peculiaridade de a capital federal estar localizada na região Centro-Oeste pode ser uma das possíveis razões para que o parâmetro não capte uma relação positiva. Ademais, capta-se uma relação positiva entre a corrente de comércio transregional e o PIB dos estados da região.

No que tange ao Sudeste, tal como o observado para as regiões Norte e Nordeste, tem-se uma relação positiva entre a corrente de comércio transregional, 0 PIB e o PIB per capita. Todavia, diferentemente do Norte e Nordeste, a relação entre o nível de renda per capita e a corrente de comércio transregional mostrou-se estatisticamente insignificante.

Por fim, para a região Sul, captou-se a relação positiva entre a corrente de comércio transregional e o PIB estadual, sinalizando que o aumento de um ponto percentual no PIB da região eleva sua corrente de comércio transregional em 1,792 pontos percentuais. Assim como o observado para o Sudeste, a relação entre o nível 
de renda per capita e a corrente de comércio transregional também mostrou-se estatisticamente insignificante.

\section{Corrente de comércio intrarregional}

Para a corrente de comércio intrarregional, diferentemente do observado para a corrente de comércio transregional, o método de estimação por EA mostrou-se o mais adequado ao conjunto de dados disponíveis.

Quadro 05: Resultados dos testes de especificação do modelo

\begin{tabular}{|l|c|}
\hline \multicolumn{1}{|c|}{ TESTES } & p-valor \\
\hline Teste de Chow & $2,60953 \mathrm{e}-005$ \\
\hline Teste de Breusch-Pagan & $6,95426 \mathrm{e}-005$ \\
\hline Teste de Hausman & 0,151339 \\
\hline
\end{tabular}

Fonte: Elaboração própria dos autores.

Em relação aos pressupostos básicos do modelo, o quadro 06 abaixo sintetiza os resultados auferidos.

Quadro 06: Resultados dos testes de especificação em relação aos pressupostos básicos do modelo de regressão

\begin{tabular}{|l|c|}
\hline \multicolumn{1}{|c|}{ TESTES } & p-valor \\
\hline Teste de Jarque Bera & 0,00024 \\
\hline Teste de Wald & - \\
\hline Teste de Durbin-Watson & 0,0443328 \\
\hline
\end{tabular}

Fonte: Elaboração própria dos autores.

Conforme verificado no quadro 06 os dados apresentaram problemas de normalidade dos resíduos e autocorrelação. Diante da quebra de tais pressupostos, tal qual o observado para a corrente de comércio transregional, foram utilizados os estimadores de mínimos quadrados ponderados.

Do ponto de vista econômico, quanto aos sinais dos parâmetros estimados no modelo, tem-se a existência de uma relação positiva entre a corrente de comércio intrarregional e o produto regional bruto, em contrapartida, capta-se uma relação inversa para com o PIB per capita. 
Tabela 04: Resultados para a corrente de comércio intrarregional

\begin{tabular}{ccccc}
\hline \multicolumn{4}{c}{ Modelo: Mínimos Quadrados Ponderados. Variável dependente: logCCINTRARREGIONAL } \\
\hline & Coeficiente & Erro Padrão & razão-t & p-valor \\
Const. & 0,257 & 0,885 & 0,2902 & 0,7724 \\
logPIB & 1,644 & 0,049 & 33,26 & $7,80 \mathrm{e}-048^{\star * *}$ \\
logPIBpercap. & $-0,972$ & 0,107 & $-9,048$ & $8,70 \mathrm{e}-014^{\star * *}$ \\
R-quadrado & 0,9364 & R-quadrado ajustado & 0,9348 \\
F(2,78) & 574,62 & P-valor (F) & $2,11 \mathrm{E}-47$ \\
Log da verossimilhança & $-113,64$ & Critério de Akaike & 233,27 \\
Critério de Schwarz & 240,45 & Critério Hannan-Quinn & 236,15
\end{tabular}

Fonte: Elaboração própria dos autores. Nota: $\left(^{*}\right)$ parâmetros estatisticamente significantes a 10\%; $\left({ }^{\star *}\right)$ parâmetros estatisticamente significantes a $5 \% ;\left(^{* \star *}\right)$ parâmetros estatisticamente significantes a $1 \%$.

Nesse caso, o aumento de um ponto percentual no produto regional bruto eleva a corrente de comércio intrarregional em 1,644 pontos percentuais. Por outro lado, o aumento de um ponto percentual no produto per capita reduz a corrente de comércio intrarregional em 0,972 pontos percentuais.

Tal como a corrente de comércio transregional, se faz necessário observar-se as regiões individualmente.

A partir da tabela 05 pode-se verificar que para a região Norte tem-se uma relação positiva entre o nível renda e os fluxos de comércios intrarregionais. Tem-se que o aumento de um ponto percentual no PIB da região eleva sua corrente de comércio intrarregional em 1,028 pontos percentuais. No que tange à relação entre 0 nível de renda per capita e a corrente de comércio intrarregional, esta mostrou-se estatisticamente insignificante.

No que tange à região Nordeste, tal como o Norte, captou-se uma relação positiva e estatisticamente insignificante entre o nível de renda per capita e a corrente de comércio intrarregional. Todavia, diferentemente do observado para 0 Norte, a relação entre o PIB e a corrente de comércio intrarregional para o Nordeste 
é inelástica, de modo que o aumento em um ponto percentual no PIB da região eleva sua corrente de comércio intrarregional em 0,636 pontos percentuais.

Tabela 05: Resultados para a corrente de comércio intrarregional por Região

\begin{tabular}{|c|c|c|c|c|}
\hline \multicolumn{5}{|c|}{$\begin{array}{c}\text { Modelo: Mínimos Quadrados Ponderados. Corrente de Comércio Intrarregional por Regiãc } \\
\text { Região Norte }\end{array}$} \\
\hline \multicolumn{5}{|c|}{ Variável Dependente: logCCINTRARREGIONAL } \\
\hline & Coeficiente & Erro Padrão & razão-t & $p$-valor \\
\hline Const. & $-17,197$ & 8,419 & $-2,043$ & $0,0560^{*}$ \\
\hline $\log P I B$ & 1,028 & 0,178 & 5,77 & $1,81 e-05^{\star * *}$ \\
\hline logPIBpercap. & 1,517 & 0,904 & 1,678 & 0,1106 \\
\hline $\begin{array}{l}\text { R-quadrado: } 0,6545 \\
F(2,18): 17,051\end{array}$ & & & $\begin{array}{l}\text { R-quadradc } \\
\text { P-valor (F): }\end{array}$ & $\begin{array}{l}\text { stado: } 0,6161 \\
00070\end{array}$ \\
\hline \multicolumn{5}{|c|}{ Região Nordeste } \\
\hline \multicolumn{5}{|c|}{ Variável Dependente: logCCINTRARREGIONAL } \\
\hline & Coeficiente & Erro Padrão & razão-t & $p$-valor \\
\hline Const. & 2,251 & 1,674 & 1,345 & 0,1913 \\
\hline $\log P I B$ & 0,636 & 0,048 & 13,1 & $1,98 \mathrm{e}-012^{\star \star \star}$ \\
\hline logPIBpercap. & 0,013 & 0,218 & 0,059 & 0,9535 \\
\hline R-quadrado: 0,9100 & & \multicolumn{3}{|c|}{ R-quadrado ajustado: 0,9025} \\
\hline$F(2,24): 121,37$ & & \multicolumn{3}{|c|}{ P-valor (F): 2,82e-13 } \\
\hline
\end{tabular}

Região Centro-Oeste

\begin{tabular}{|c|c|c|c|c|}
\hline \multicolumn{5}{|c|}{ Região Centro-Oeste } \\
\hline \multicolumn{5}{|c|}{ Variável Dependente: logCCINTRARREGIONAL } \\
\hline & Coeficiente & Erro Padrão & razão-t & $p$-valor \\
\hline Const. & 3,678 & 0,828 & 4,443 & $0,0016^{* * *}$ \\
\hline $\log P I B$ & 1,011 & 0,101 & 9,995 & $3,59 \mathrm{e}-06^{\star \star \star}$ \\
\hline logPIBpercap. & $-0,653$ & 0,092 & $-7,086$ & $5,75 \mathrm{e}-05^{\star \star \star}$ \\
\hline R-quadrado: 0,9177 & & \multicolumn{3}{|c|}{ R-quadrado ajustado: 0,8994} \\
\hline$F(2,9): 50,163$ & \multicolumn{4}{|c|}{ P-valor (F): 0,000013} \\
\hline \multicolumn{5}{|c|}{$\begin{array}{c}\text { Região Sudeste } \\
\end{array}$} \\
\hline \multicolumn{5}{|c|}{ Variável Dependente: logCCINTRARREGIONAL } \\
\hline & Coeficiente & Erro Padrão & razão-t & p-valor \\
\hline Const. & 9,331 & 0,777 & 12 & $7,70 \mathrm{e}-07^{* \star *}$ \\
\hline $\log \mathrm{PIB}$ & 0,703 & 0,02 & 34,22 & $7,66 \mathrm{e}-011^{* * *}$ \\
\hline logPIBpcap. & $-0,650$ & 0,085 & $-7,615$ & $3,27 \mathrm{e}-05^{\star \star \star}$ \\
\hline $\begin{array}{l}\text { R-quadrado: } 0,9924 \\
F(2,9): 586,439\end{array}$ & & & $\begin{array}{l}\text { quadrado } \\
\text { ralor (F): }\end{array}$ & $\begin{array}{l}\text { tado: } 0,9907 \\
\text { e-10 }\end{array}$ \\
\hline \multicolumn{5}{|c|}{ 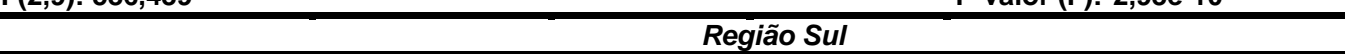 } \\
\hline \multicolumn{5}{|c|}{ Variável Dependente: logCCINTRARREGIONAL } \\
\hline & Coeficiente & Erro Padrão & razão-t & $p$-valor \\
\hline Const. & 15,577 & 2,037 & 7,648 & $0,0003^{* * *}$ \\
\hline $\log P I B$ & $-0,296$ & 0,096 & $-3,097$ & $0,0212^{\star *}$ \\
\hline logPIBpercap. & $-0,176$ & 0,167 & $-1,055$ & 0,3321 \\
\hline $\begin{array}{l}\text { R-quadrado: } 0,6282 \\
F(2,6): 5,07\end{array}$ & & \multicolumn{3}{|c|}{$\begin{array}{l}\text { R-quadrado ajustado: } 0,5043 \\
\text { P-valor (F): } 0,051374\end{array}$} \\
\hline
\end{tabular}

Fonte: Elaboração própria dos autores. Nota: $\left({ }^{*}\right)$ parâmetros estatisticamente significantes a 10\%; $\left({ }^{* *}\right)$ parâmetros estatisticamente significantes a $5 \% ;\left({ }^{* * *}\right)$ parâmetros estatisticamente significantes a $1 \%$.

Tal como para a corrente transregional, a corrente de comércio intrarregional do Centro-Oeste relaciona-se positivamente com o PIB e negativamente com o PIB per capita. Nesse caso, o aumento de um ponto percentual no PIB dos estados que compõem a região eleva a corrente de comércio intrarregional em 1,011 pontos 
percentuais. Por outro lado, o aumento de um ponto percentual no produto per capita reduz a corrente de comércio intrarregional em 0,653 pontos percentuais.

No tocante ao Sudeste, captou-se a existência de uma relação positiva entre a corrente de comércio intrarregional e o PIB, e uma relação negativa com o nível de renda per capita. Ademais, diferentemente das demais regiões, tem-se uma relação negativa entre o PIB e a corrente de comércio intrarregional do Sul e, tal como o observado para o Centro-Oeste e Sudeste, uma relação negativa para com o PIB per capita.

\section{Considerações Finais}

Neste trabalho analisa-se o comércio por vias internas do país nos anos de 1998 e 2008 ao passo que há a tentativa de verificar-se como o comércio interregional relaciona-se com o produto regional bruto e o nível de renda per capita regional, ou seja, verificar qual dos fluxos comerciais inerentes ou externos às regiões relacionam-se com maiores níveis de desenvolvimento captados pelo PIB e PIB per capita dos estados e regiões analisadas.

É possível evidenciar alguns resultados. Por exemplo, em 2008:

i) Na região Norte, observa-se que os estados da região são dependentes do comércio praticado externamente a região, pois 94,27\% das exportações e 95,13\% das importações dos estados da região, por vias internas, representam o comércio com o restante do país. Quanto ao saldo da balança comercial e de serviços da região, em conjunto os estados do Norte são superavitários apenas em relação aos do Nordeste;

ii) Para os estados do Nordeste aproximadamente $76 \%$ de suas exportações e $84,14 \%$ de suas importações interestaduais são relativas ao comércio transregional. Ademais, o Nordeste brasileiro mantém uma relação deficitária com as demais regiões do país, e individualmente todos os estados apresentam saldos transregionais deficitários;

iii) Do montante de exportações e importações dos estados da região Centro Oeste para os demais estados do país apenas $9,80 \%$ e $7,32 \%$, respectivamente, destas representam o comércio intrarregional. Observando-se o saldo da balança comercial e de serviços dos estados da região em conjunto, em relação às demais regiões do país, notam-se superavits em relação ao Norte e ao Nordeste, e deficits com o Sul e, principalmente, o Sudeste; 
iv) O comércio intrarregional dos estados do Sudeste responde por $54,9 \%$ de suas exportações interestaduais. No tocante as importações, $51,41 \%$ das mesmas representam trocas comerciais entre os estados do Sudeste. Quanto ao saldo da balança comercial e de serviços da região, o Sudeste mantém superavits em relação às demais regiões;

v) No tocante a região Sul, $81,45 \%$ das exportações interestaduais de seus estados têm como destino as demais regiões do país. Quanto às importações $81,23 \%$ do total importado domesticamente pelos estados da região procedem das demais regiões. Cabe ainda ressaltar que a região Sul é deficitária em relação ao Sudeste, e superavitária em relação às demais regiões do país.

Assim, é possível chamar a atenção para o grau de dependência comercial das demais regiões em relação à região Sudeste (em especial ao estado de São Paulo), pois a mesma mantém balança comercial e de serviços superavitária em relação às demais regiões do país sendo responsável pelo destino de mais de $40 \%$ da pauta de exportações e importações das demais regiões. Verifica-se uma grande concentração dos fluxos de comércio originados da porção Centro-Sul do país e, em geral, os fluxos interestaduais têm importância relativa maior para os estados menos desenvolvidos do país.

No tocante ao fluxo de comércio (transregional e intrarregional) percebe-se que o mesmo apresenta relação positiva com o produto regional bruto, o que implica que o comércio por vias internas pode constituir-se como uma importante via de crescimento econômico. No que concerne à relação com o PIB per capita, os resultados são ambíguos. Capta-se, no nível agregado, uma relação positiva com a corrente de comércio transregional e uma relação negativa com os fluxos de comércio intrarregionais. Todavia, quando consideradas as regiões individualmente, verifica-se uma relação positiva entre o PIB per capita e a corrente de comércio intrarregional dos estados das regiões de menor nível de desenvolvimento. Portanto, os resultados das estimações para os dois fluxos de comércio, transregional e intrarregional, e a análise do comércio por vias internas apontam para ampliação de evidências favoráveis à hipótese lançada no presente trabalho de que a maior integração comercial entre os estados relaciona-se positivamente com maiores níveis de renda.

A análise dos fluxos de comércio por vias internas possibilita a compreensão e avaliação das relações comerciais entre os estados e regiões, a utilização dos produtos importados pelos mesmos, a natureza das atividades econômicas, os 
encadeamentos existentes entre suas estruturas produtivas, bem como o grau de (in)dependência econômica dos mesmos. Tais pontos levantados são futuros tópicos a serem estudados para melhor decifrar-se como se dá a relação comercial interregional entre os estados da Federação.

\section{REFERÊNCIAS}

ALMEIDA, F. M.; SILVA, O. M. Comércio e integração dos estados brasileiros. Revista de Economia e Agronegócio, Viçosa, v. 5, n. 4, p. 487-499, 2007. Disponível em: https://revistarea.ufv.br/index.php/rea/article/view/114/120. Acesso em 05 jan 2017.

CANO, W. Desequilíbrios regionais e concentração industrial no Brasil, 1930-1970. São Paulo. Ed. Global. UNICAMP, 1985.

CASTRO, N.; CARRIS, L.; RODRIGUES, B. Custos de transporte e a estrutura espacial do comércio interestadual brasileiro. Revista Pesquisa e Planejamento Econômico, Rio de Janeiro, v. 29, n. 3, p. 347-400, dez. 1999. Disponível em:

http://ppe.ipea.gov.br/index.php/ppe/article/viewFile/181/116. Acesso em 05 jan 2017.

GALVÃO, O. A. Comércio interestadual por vias internas e integração regional no Brasil. Encontro Nacional de Economia, Belo Horizonte. Anais... Belo Horizonte/MG: ANPEC, 1993, v. 1 p $257-79$.

GUILHOTO, J. J. M.; AZZONI, C. R.; ICHIHARA, S. M.; KADOTA, D. K.; HADDAD, E. A. Matriz de Insumo-Produto do Nordeste e Estados: Metodologia e Resultados.

Fortaleza: Banco do Nordeste do Brasil. ISBN: 978.85.7791.110.3. 289 p., 2010.

GUILHOTO, J. J. M.; SESSO FILHO, U. A. Estimação da Matriz Insumo-Produto Utilizando Dados Preliminares das Contas Nacionais: Aplicação e Análise de Indicadores Econômicos para o Brasil em 2005. Economia \& Tecnologia, v. 6, n. 4, p. 53-62, out./dez. 2010.

GUJARATI, D. N.; PORTER, D. C. Econometria Básica, 5. ed., AMGH Editora Ltda, 2011.

HADDAD, P. R. Tendências recentes do comércio internacional e suas implicações para a economia de Minas. Cadernos BDMG. Belo Horizonte, n.6, p. 4-63, fev. 2003.

MAGALHÃES, A. S.; DOMINGUES, E. P. Relações interestaduais e intersetoriais de comércio no Brasil: Uma análise gravitacional e regional. 2007. Disponível em: http://www.anpec.org.br/encontro2007/artigos/A07A142.pdf. Acesso em: 07/01/2017.

PACHECO, C. A. Fragmentação da Nação. Campinas, São Paulo: IE/Unicamp, 1998.

PEROBELLI, F. S.; HADDAD, E. A., DOMINGUES; E. P. Interdependence among the Brazilian States: an Input-Output approach. In: XXXIV Encontro Nacional de Economia, Salvador. Anais... Salvador/BA: ANPEC, 2006.

PEROBELLI, F. S.; HADDAD, E. A.; MOTTA, G. P.; FARINAZZO, R. A. Estrutura de comércio inter-regional no Brasil: uma análise espacial de insumo produto para 0 período 1996 e 2002. 2008. Disponível em:

http://www.anpec.org.br/encontro2008/artigos/200807171627000-.pdf. Acesso em: 08/01/2017. 
VASCONCELOS, J. R. Matriz do fluxo de comércio interestadual de bens e serviços no Brasil: 1998. Brasília, DF: IPEA,2001. (Texto para Discussão-IPEA, n. 783).

VASCONCELOS, J. R.; OLIVEIRA, M. A. Análise da matriz por atividade do comércio interestadual no Brasil: 1999. Rio de Janeiro: IPEA, 2006. (Texto para Discussão IPEA, n. 1159).

WOOLDRIDGE, J. M. Econometric analysis of cross section and panel data. Cambridge, Mass.: MIT Press, 2002.

\section{NOTAS DE AUTOR}

\section{CONTRIBUIÇÃO DE AUTORIA}

Joelson Oliveira Santos - Concepção e elaboração do manuscrito, Coleta de dados, Análise de dados, Elaboração do manuscrito, Participação ativa da discussão dos resultados.

Prof. Dr. André Luís Cabral de Lourenço - Orientação, Revisão e aprovação da versão final do trabalho.

\section{FINANCIAMENTO}

Pesquisa fomentada pela Pró-Reitoria de Pesquisa da Universidade Federal do Rio Grande do Norte PROPESQ/UFRN, edital $n^{\circ} 01 / 2017$.

\section{CONSENTIMENTO DE USO DE IMAGEM}

Não se aplica.

\section{APROVAÇÃO DE COMITÊ DE ÉTICA EM PESQUISA}

Não se aplica.

\section{CONFLITO DE INTERESSES}

Não há.

\section{LICENÇA DE USO}

Este artigo está licenciado sob a Licença Creative Commons CC-BY. Com essa licença você pode compartilhar, adaptar, criar para qualquer fim, desde que atribua a autoria da obra.

\section{HISTÓRICO}

Recebido em: 15-10-2018

Aprovado em: 09-01-2020 